\title{
Understanding Part Fabrication Errors in Closed-Loop Machining Systems
}

Herbert T. Bandy

Lawrence A. Welsch 

NISTIR 6876

\title{
Understanding Part Fabrication Errors in Closed-Loop Machining Systems
}

\author{
Herbert T. Bandy \\ Lawrence A. Welsch \\ Manufacturing Metrology Division \\ Manufacturing Engineering Laboratory \\ National Institute of Standards and Technology \\ Gaithersburg, MD 20899-8220
}

June 2002

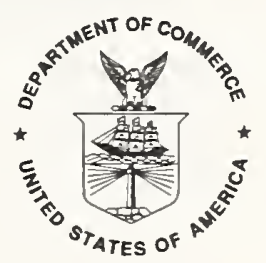

U.S. Department of Commerce

Donald L. Evans, Secretary

Technology Administration

Phillip J. Bond. Under Secretary for Technology

National Institute of Standards and Technology Arden L. Bement, Jr., Director 



\title{
Understanding Part Fabrication Errors in Closed-Loop Machining Systems
}

\author{
Herbert T. Bandy and Lawrence A. Welsch, Ph.D.
}

\begin{abstract}
This paper presents an analysis of part fabrication errors (part dimension and form deviations) in closed-loop machining systems. Modeling methods are used to situate error components in the context of other error components to clarify the effects of error compensation. Several novel concepts are introduced to make complex relationships between error components easily comprehensible.

Inspection data are considered for one gauging point at a time. The part's physical surface detected by a touch-trigger probe during inspection is held as a fixed reference. When errors are calculated from measurements and used to locate the nominal surface with respect to the detected surface, this derived location of the nominal surface depends on the accuracy of the measuring instrument. If a probe on a machine tool is used to inspect the part, any discrepancy in the location of the derived "nominal surface" (when compared to the location of the nominal surface in the part coordinate system used during machining) reflects the machine tool geometric errors. A method of organizing the error components was developed to take advantage of this fact and discern the effects of machine tool geometric errors among other errors.
\end{abstract}

Another useful concept introduced is the hypothetical uncompensated surface. Inspection would detect the surface at this location if the part were machined without error compensation. This and other hypothetical locations are used to illustrate the requirements for machining with error compensation to produce a detected surface that approaches the nominal location.

The concepts explained should help with interpreting inspection data, decomposing errors into components, distinguishing the contributions of error compensation adjustments, and locating nominal surfaces for error computations.

The paper also presents a description of how to structure error and error compensation data into distinct classes in closed-loop machining systems. 


\section{Table of Contents}

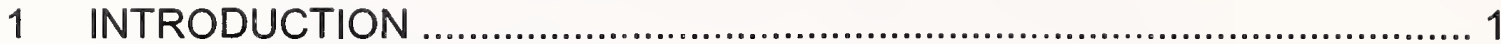

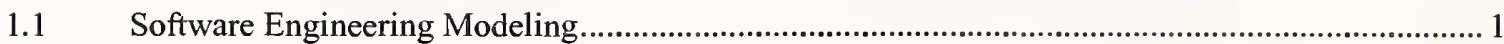

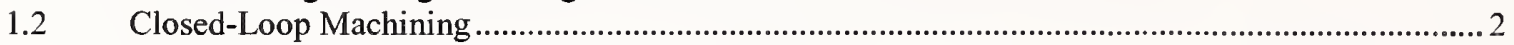

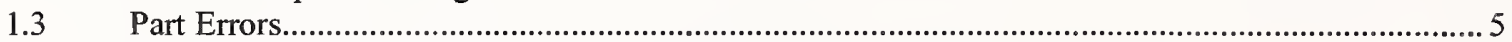

2 A SOFTWARE FRAMEWORK FOR DESCRIBING ERRORS .................... 7

3 CLARIFYING PART ERRORS, PART ERROR COMPONENTS, AND ERROR COMPENSATION ............................................................... 9

3.1 Part Coordinate System Discrepancy …….............................................................................. 10

3.2 Machining Without Error Compensation ................................................................................. 13

3.3 Accounting for Machine Tool Geometric Errors........................................................................ 15

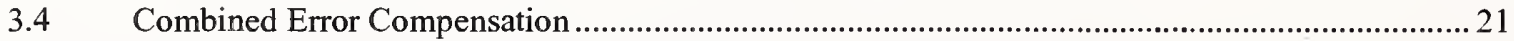

3.5 Distinguishing Process Errors and Machine Tool Geometric Errors............................................... 22

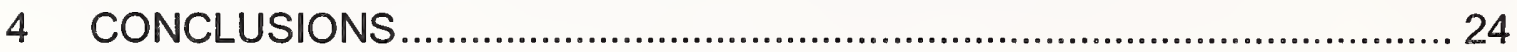

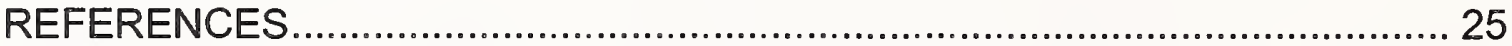

APPENDIX I: UML CONVENTIONS USED IN THIS ARTICLE....................... 26

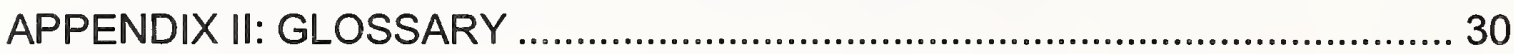

Figures

Figure 1. The part surface location depends on how much of the potential error is compensated.................. 3

Figure 2. The error compensation strategy of closed-loop machining.......................................................... 4

Figure 3. The error vector extends from the nominal surface location to the detected surface...................... 5

Figure 4. The total error is the resultant of the applicable error components............................................... 6

Figure 5. An activity diagram for closed-loop machining. ...................................................................... 7

Figure 6. The part coordinate system discrepancy................................................................................. 11

Figure 7. Error components for a part machined without error compensation................................................. 13

Figure 8. Basic vector relationships. ................................................................................................................ 15

Figure 9. The probe position reported by the machine tool controller is inaccurate due to machine tool

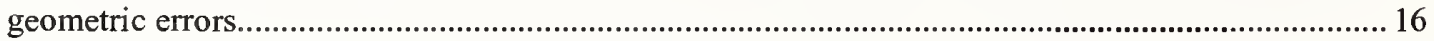

Figure 10. The GT model is used to compute coordinate adjustments to account for machine tool

geometric errors at cutting temperatures and probing temperatures.................................................... 17

Figure 11. The placement of an error compensation vector in a conceptual picture can be misleading..... 18

Figure 12. Compensation of machine tool geometric errors. ...................................................................... 19

Figure 13. Combined compensation of both machine tool geometric errors and process errors. ................. 21

Figure 14. Residual errors may remain after error compensation has been applied. ...................................22

Figure 15. The error compensation vectors may be arranged and placed in a conceptual picture to show how error compensation changed the position of the part surface......................................................... 23

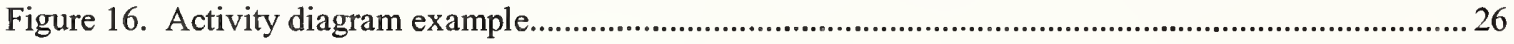

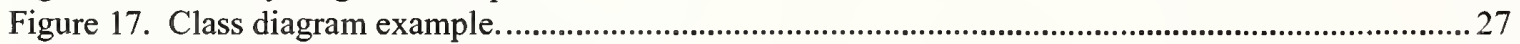

Figure 18. Second class diagram example.................................................................................................. 29 


\section{Introduction}

This paper clarifies the relationships between different types of part errors ${ }^{1}$ involved in error compensation for closed-loop machining. Measurement errors-i.e., inaccuracies due to operator performance, or to the geometry, action, response, or repeatability of measurement instrumentation, etc.- - are not within the scope of the discussion, with the exception of machine tool geometric errors.

The paper uses diagrams, equations, software engineering modeling techniques, and exposition to describe the relationships between the different types of part errors. One benefit is to enhance the understanding of part error data to facilitate the development of error compensation algorithms and related software. Another benefit is to provide a way to organize the representation of error and error compensation data for closed-loop machining systems.

The paper addresses a scenario with a closed-loop machining system that includes a machine tool, nominal part design and inspection data, a geometric-thermal (GT) model of the machine tool, process-intermittent error compensation capability with an onmachine dimensional inspection probe, a coordinate measuring machine (CMM), and other features. Section 1.2 provides a brief description of closed-loop machining. Section 3 and its subsections organize the errors involved in closed-loop machining to help understand how to write error compensation software.

The rest of the introduction provides a brief description of software engineering modeling, closed-loop machining, and part errors. Following the introduction, the paper presents a framework ${ }^{2}$ in Section 2 for understanding part errors in closed-loop machining. That section presents a software engineering model of part errors and part error components, as well as diagrams showing the relationships between errors and part surface locations.

\subsection{Software Engineering Modeling}

The goal of building a software-engineering model of machining errors is to clarify the requirements of error compensation strategies. To improve the performance of machine tools, software and hardware are used to implement algorithms to compensate machine tool errors. The algorithms compensate two types of errors: machine tool geometric errors that are inherent in the machine tool, and process errors caused by the cutting process. Using the latest software engineering techniques to model the errors helps:

1. view machining errors from a perspective that allows better understanding of them by exposing aspects that were not apparent;

2. ensure consistent treatment of errors by more precisely capturing the semantics (meanings) of the different parts of the model as well as the interrelationships between those parts; and

3. increase the likelihood that the design of error compensation software is correct.

\footnotetext{
${ }^{1}$ The use of the term error in this article is explained in section 1.2.

${ }^{2}$ Framework in the sense of a context to place part errors and error compensation vectors.
} 
The Unified Modeling Language (UML) [Rumbaugh 1998] was chosen to model part error for the following reasons:

1. UML has a visual component, meaning that one product is a collection of graphic diagrams that show the relationships between parts of the model more clearly than a non-visual description;

2. UML is a formal language with precise syntax and semantics;

3. UML combines different aspects of object-oriented analysis and design [Booch 1998], object-oriented modeling [Booch 1993][Rumbaugh 1990][Meyer 1997], use case analysis ${ }^{3}$ [Jacobson 1992] and other modeling techniques; and

4. Industry consortia such as the Object Management Group (OMG) [OMG 2001] are adopting UML.

UML notation conventions will be explained as they are first used. For explanations of all the UML conventions used, see Appendix I: UML Conventions Used in This Article.

\subsection{Closed-Loop Machining}

One of the most important objectives in manufacturing is for each product to conform as closely as possible to its design specifications. Each part should be fabricated to minimize deviations from nominal form and dimensions. In this report, such deviations are referred to as part errors. ${ }^{4}$ One approach to reducing part errors is to characterize, predict, and compensate systematic errors during fabrication. The methodology for accomplishing this is called closed-loop machining. With properly formulated and implemented error compensation routines, closed-loop machining can be a very effective approach to minimizing part errors [Bandy 2001][Donmez 1986].

Closed-loop machining [Donmez 1991] uses strategies to control the machining process to compensate systematic errors according to tendencies determined in advance. An error detected on a part is actually the sum of contributions from various sources. In closedloop machining, sources are identified and error contributions are quantified. According to the resultant error at each point on the workpiece, the cutting tool position is adjusted during machining to compensate the errors. To better understand the effects of closedloop machining, one has to consider the possible locations of a part surface that may result from the motion of a cutting tool against the workpiece. Figure 1 considers a point on a part surface machined with error compensation. The location of the point is compared to its nominal location and its hypothetical location if the surface were machined without error compensation.

\footnotetext{
${ }^{3}$ Section 2 uses a part of use case analysis called an activity diagram to provide a framework for the part error model.

${ }^{4}$ According to the International Vocabulary of Basic and General Terms in Metrology (VIM) [ISO 1993], a publication of the International Organization for Standardization (ISO), the preferred term for this definition is "deviation" rather than "error." The term "error compensation" in this report is consistent with common reference to reducing measured part size discrepancies. With terms explained prior to discussions, the authors feel that in the context of this report, the common usage of "error" has clear meaning and reads less tediously than would the proper usage of "deviation."
} 


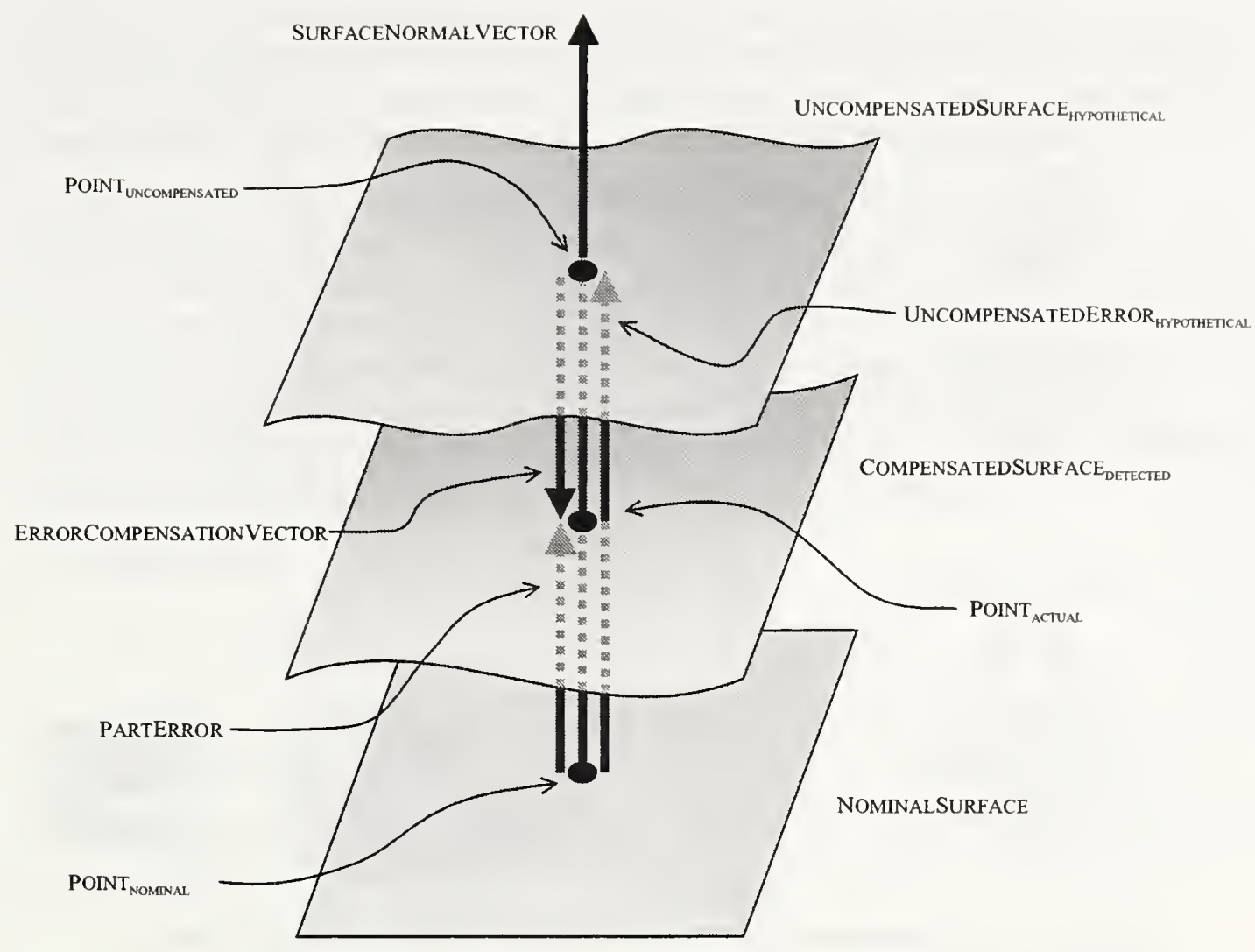

Figure 1. The part surface location depends on how much of the potential error is compensated.

The NOMINALSURFACE is the ideal location, according to the design specification. If the part were machined without error compensation, the error tendency of machining would offset the cutting tool by UNCOMPENSATEDERROR HYPOTHETICAL $_{\text {to }}$ produce the UNCOMPENSATEDSURFACE HYPOTHETICAL. In an attempt to reverse the effect of

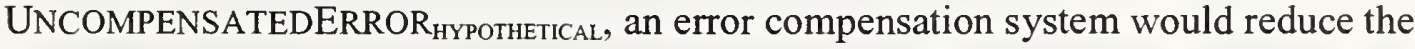
potential error by the ERRORCOMPENSATIONVECTOR, positioning the cutting tool to

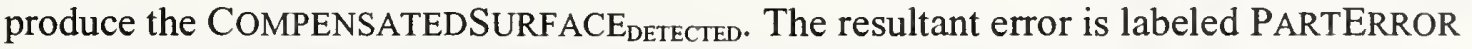
in this simple example. Note that the part error relationships studied in this paper are considered at a single point at a time-usually a gauging point, a target for inspection. As shown in Figure 1, the location of a part surface at a gauging point is the intersection of the surface with the surface normal vector at the gauging point. In this context, the part surface is known only as a location on the surface normal vector. For more detailed explanations of terms, see the Glossary in Appendix II. As the article proceeds, these and additional error components and contributing vectors will be systematically considered. 


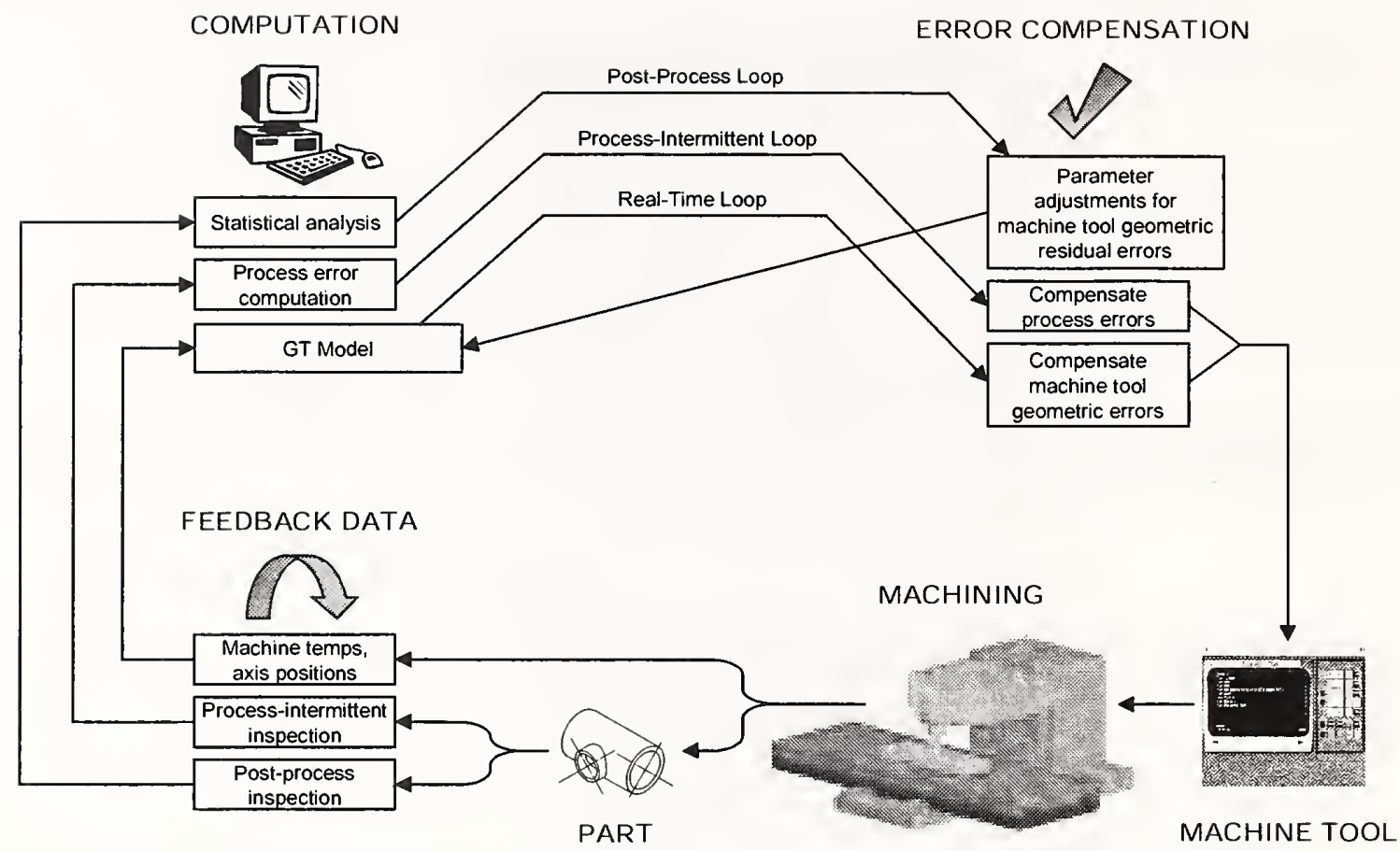

Figure 2. The error compensation strategy of closed-loop machining.

A typical implementation of closed-loop machining uses three control loops: the realtime, process-intermittent, and post-process loops. Each loop characterizes error patterns that are used in different error compensation algorithms. The control loops are shown in Figure 2.

The real-time control loop addresses the machine tool geometric errors, the quasi-static or thermally induced distortions in machine tool geometry. Example causes are problems with the angular error motion of a cross-slide, the straightness of carriage motion, or the squareness between the motions of the carriage and cross-slide. A GT model of the machine tool is required to estimate inaccuracies in tool position as a function of nominal position, direction of tool motion (to account for backlash), and machine temperatures. Position feedback, computations, and tool position adjustments are implemented in realtime during machining.

In the process-intermittent control loop [Bandy 2001], fabrication is stopped after a "semi-finish" cut, leaving only enough material for a finish cut to complete the part. The machine tool performs dimensional inspection using a touch-trigger probe to determine errors resulting from the semi-finish cut. (The real-time control loop is not operational during probing because the probe triggers and coordinates are recorded when the probe contacts the part, regardless of any attempted position adjustments by the controller.) With the expectation that the finish cut would tend to induce similar errors, the parameters to compensate the errors during the finish cut are derived. Since under ideal conditions the errors dealt with by the process-intermittent control loop are measured by the machine tool itself, the machine tool's own geometric errors are not detected. 
Therefore, the process-intermittent control loop isolates and compensates process errors: those part error components caused by problems with the cutting process, unrelated to machine tool geometry. These errors are attributable to such causes as length, wear, or deflection of the tool; or location, clamping, or deflection of the workpiece.

The post-process control loop is used to refine the GT model as machine tool characteristics may change over time (perhaps months). Each finished part is inspected on the machine tool before it is removed. Then it is inspected on a CMM. A post-process analysis is performed on data from many parts. The average difference in the measurements for each gauging point is the machine tool geometric residual error, the amount of error not compensated by the real-time control loop. The machine tool geometric residual error indicates the need for adjustments in the GT model. The model is refined accordingly for subsequent use in the real-time control loop.

\subsection{Part Errors}

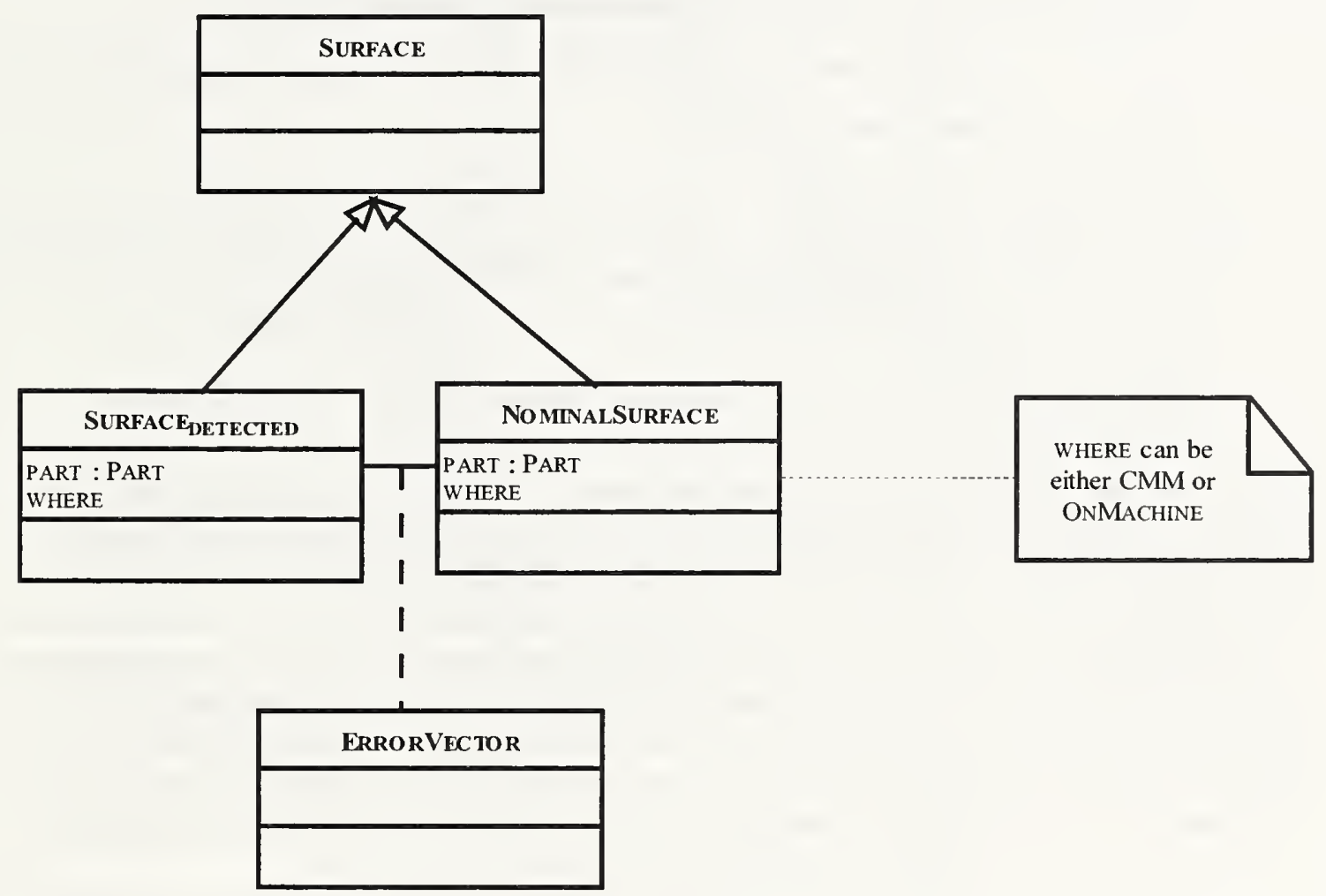

Figure 3. The error vector extends from the nominal surface location to the detected surface.

As the term is used in this paper, a part error is the surface normal vector originating from the nominal coordinates of a point on the part, and extending to the measured location of the part surface. (For more specific information, see the definition of PARTERROR in the Glossary in Appendix II.) Figure 3 shows a UML model of a part error. The rectangles represent different classes. The clear arrowhead indicates that one class is a 
generalization of another. Thus, SURFACE DeteCTED and NOMINALSURFACE are generalizations of SURFACE. The attributes and operations are shown in the rectangles immediately below the class name, respectively. The SURFACEDETECTED and NOMINALSURFACE are associated by means of an ERRORVECTOR. A note indicates that a NOMINALSURFACE may be as determined on a CMM or a machine tool.

Implicit in Figure 3 is a way to structure the data. Thus a closed-loop machining system should have data corresponding to instances of SURFACE ERRORVECTOR.

As mentioned earlier, part errors consist of the combination of process errors and machine tool geometric errors. Process errors and machine tool geometric errors, as described in Section 2 below, are differentiated, but their causes, such as tool deflection or axis tilt, are not addressed.

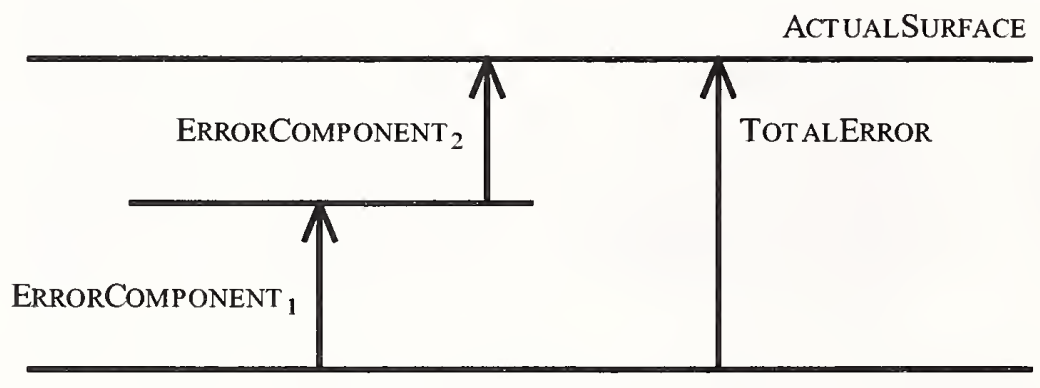

NOMINALSURFACE

Figure 4. The total error is the resultant of the applicable error components.

If the errors are considered for each gauging point at a time, all contributing vectors are collinear, normal to the nominal part surface and passing through the nominal gauging point. With this approach, the problem of resolving the components is reduced to onedimension. However, the figures in this report will schematically depict error components at a single gauging point as a set of parallel vectors, separated for clarity of visualization. If the example in Figure 4 represents the error components at a single gauging point, it should be understood that all the vectors are actually collinear. In all the figures, as well as the discussions, the different types of vectors and surfaces are defined in the Glossary in Appendix II. (An exception is the terms used in Closed-Loop Machining, which are descriptive concepts rather than specific nomenclature.) 


\section{A Software Framework for Describing Errors}

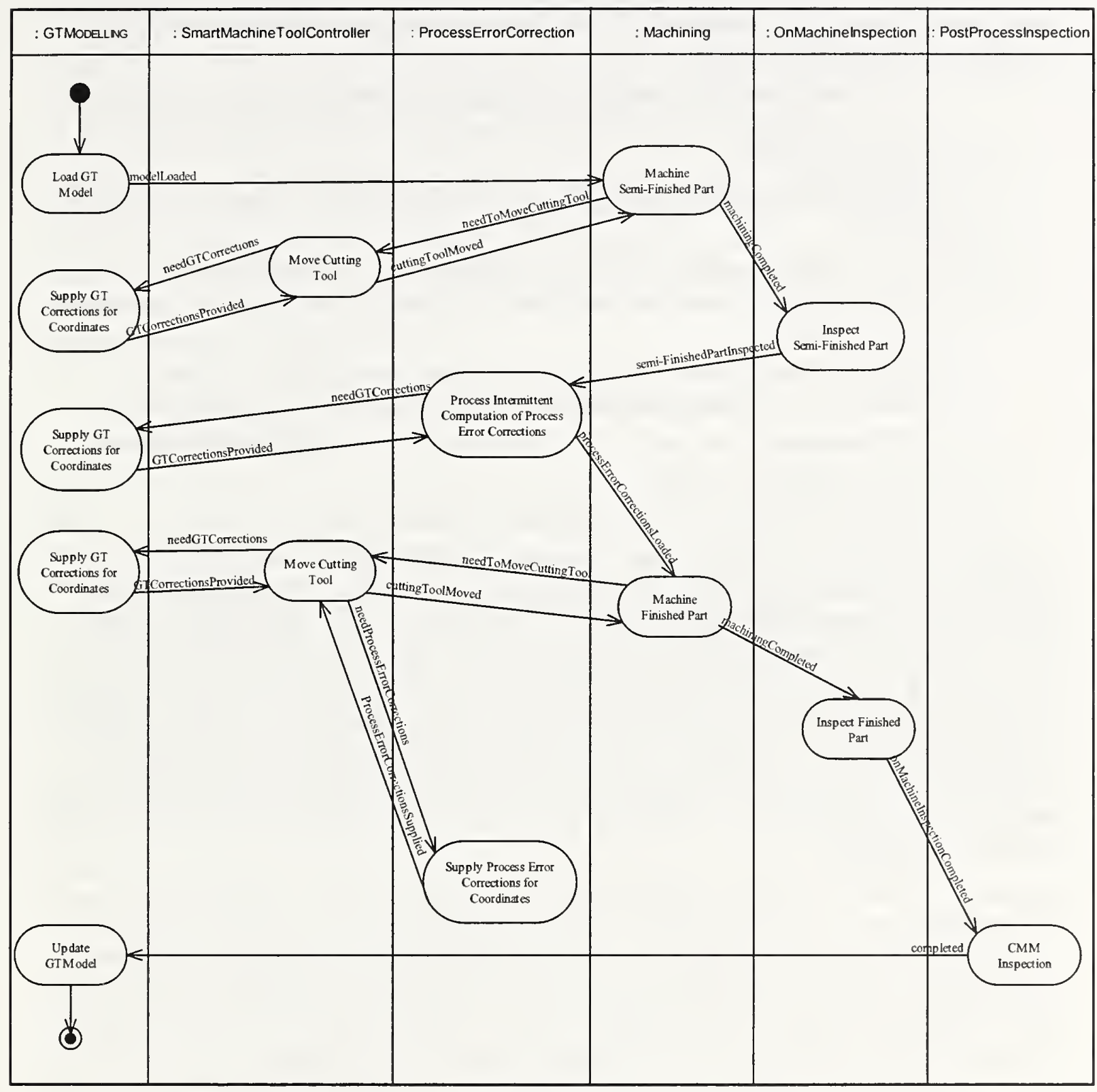

Figure 5. An activity diagram for closed-loop machining.

Figure 5 above uses the Unified Modeling Language, UML, to model closed-loop machining using an activity diagram. An activity diagram in UML is a diagram that shows the flow from activity to activity, addressing the dynamic view of a system.

The boxes across the top of the figure show instances of different logical collections of operations and data. In UML, these instances are referred to as class instances or objects. A class is a description of a set of objects that share attributes, operations, relationships 
and semantics. An object is a concrete manifestation of an abstraction; an entity with a well-defined boundary and identity that encapsulates state and behavior; an instance of a class. The name of the class is to the right of the ":" and the name of the object is to the left. Since there is only one object per class, there can be no confusion when using the class name and the object names are elided. The six objects involved are an instance of one of the following five classes:

1. GTModeling (geometric-thermal modeling) includes the activities a) Load GT Model; b) Supply GT Corrections for Coordinates (repeated three times); and c) Update GTModel;

2. SmartMachineToolController includes the activity Move Cutting Tool (repeated twice);

3. ProcessErrorCorrection includes the activity Process Intermittent Computation of Process Error Corrections and the activity Supply Process Error Corrections for Coordinates;

4. Machining cuts the part as specified. Machining includes the activities of Machine Semi-Finished Part and Machine Finished Part;

5. OnMachineInspection includes the activities Inspect Semi-Finished Part and Inspect Finished Part; and

6. PostProcessInspection includes the activity CMM Inspection.

The lines separating the objects denote swimlanes. A swimlane is a partition on an activity diagram for organizing the responsibilities for activities. ${ }^{5}$ The boxes with the half circles at either end are the activities. The arrows are events. When events occur, control is passed from one activity to another. The start-state for the activity model is the solid circle in the upper left part of the diagram. The end-state for the activity model is the solid circle inside of a circle in the lower left part of the diagram. The start-state and end-state are not part of any class, and hence were placed closest to the first and last activities. The decisions as to which activity was the responsibility for which object was made based upon where first the data and second the operations used by an activity were logically associated.

Figure 5 is meant to be largely self-explanatory. The titles of the activities and the events are self-descriptive. Events may occur multiple times during the execution of an activity. For example, while the Machine Semi-Finished Part activity is executing, the event needToMoveCuttingTool will occur several times. Each time control will be passed to the Move Cutting Tool activity. After the tool has been moved, control will be passed back to the Machine Semi-Finished Part activity and the loop will repeat itself.

The real-time control loop described in Section 1.2, Closed-Loop Machining, is performed by the SmartMachineToolController activity Move Cutting Tool. Therefore, the GTModeling activity Supply GT Correction for Coordinates must operate in realtime. Further, the addition of the process error compensation vectors ("Process Error Corrections") to the machine tool geometric error compensation vectors ("GT

\footnotetext{
${ }^{5}$ This generalization is used for the sake of making the paper more readable. Swimlanes are actually for all interaction diagrams, of which activity diagrams are a subset. The responsibilities apply to actions, which in an activity diagram are the result of performing an activity.
} 
Corrections") needs to be performed rapidly and correctly by the Move Cutting Tool activity when control is passed from the Machine Finished Part activity.

The process-intermittent control loop described in Section 1.2 starts with the activity Machine Semi-Finished Part and ends with the event ending the activity Machine Finished Part. The objective of the loop is that the second time the part is cut (i.e., the finished stage of the part), the machine tool uses process error corrections based on the inspection performed after the previous cut (the semi-finished stage).

For the post-process control loop, the GTModeling activity Supply GT Correction for Coordinates is used as described above to compensate machine tool geometric errors on many parts. A statistical analysis compares the results of the OnMachineInspection activity Inspect Finished Part and the PostProcessInspection activity CMM inspection. Machine tool geometric residual errors are determined, and parameters in the GT model are adjusted, as indicated by the GTModeling activity Update GT Model, to reduce the residual errors in subsequent parts.

\section{Clarifying Part Errors, Part Error Components, and Error Compensation}

To help clarify the various elements involved in error compensation, this article makes use of a unique type of diagram, referred to here as a "surface/error" diagram. It was developed to show at once the relative magnitudes and directions of all the error vector components and error compensation vectors involved at a single gauging point on a part surface. Even though all the vectors are actually collinear, the diagram separates them for visual clarity. The diagram uses the assumption that the "detected surface," the part's physical surface that is contacted by the probe stylus during inspection, is a fixed reference. All errors are viewed with respect to the detected surface whether they are determined by on-machine inspection (using a probe controlled by the machine tool) or by post-process inspection (on a CMM). An error at a gauging point is defined as the surface normal vector originating from known coordinates on the nominal location of the surface, and terminating at the detected surface. Then, if the nominal location of the surface were unknown, it could be determined with respect to the detected surface.

A consequence of this viewpoint is that the nominal part surface for the consideration of on-machine errors is not necessarily found at the same location as that for post-process errors. The errors found by CMM inspection include components that are not detectable by on-machine inspection: the machine tool geometric errors. The two derived nominal surface locations will coincide only when the machine tool geometric errors are completely compensated during machining. Otherwise, the paradox is caused by inaccurate measurements by the machine tool due to its geometric errors. While it is understood that there is actually only one nominal location for a gauging point, the apparent disparity is conveniently exploited by surface/error diagrams, as explained below.

Surface/error diagrams allow error and error compensation vector components to be arrayed between the actual and hypothetical surface locations used to define them. They can also show the change in the location of a surface if error compensation is applied or improved. The surface locations used in this article are NOMINALSURFACE ${ }_{M T}$, 
NOMINALSURFACE $\mathrm{CMM}_{\mathrm{M}}$, COMPENSATEDSURFACE, GTCOMPENSATEDSURFACE,

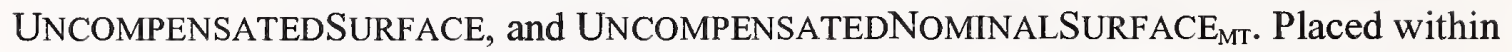
the pertinent spans between surface locations are the vector components COMP $\mathrm{MTG}_{\text {, }}$

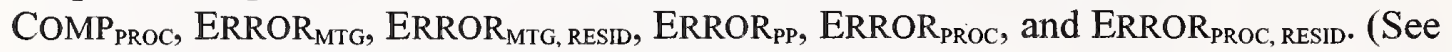
Appendix II for definitions of the named surface locations and vector components.) In most cases, the validity of the placement of a vector in the diagram is easily seen. In the case of the machine tool geometric error, the vector is shown from the nominal surface location found with the CMM to the derived nominal surface location for on-machine errors, defined as explained above. (Examples may be seen in Figure 7 and later figures.)

Using this approach to study the effects of error and error compensation vector components, one may easily formulate equations to use in error compensation algorithms. This is demonstrated using various figures throughout the rest of this article.

The next three sections provide a UML representation and a surface/error representation of the data collected when there is machining without error compensation, machining with only machine tool geometric error compensation, and machining with both process error compensation and machine tool geometric error compensation. The section ends with a discussion of how to distinguish machine tool geometric errors from process errors.

\subsection{Part Coordinate System Discrepancy}

Sections 1.2 and 1.3 described closed-loop machining and part errors. Part errors depend on the location of the part surface. To explore different potential errors, this article considers several possible locations of a part surface. As explained above, on-machine errors are used to derive a hypothetical surface nominal location denoted as NOMINALSURFACE $_{M T}$. The machine tool geometric error separates this location from NOMINALSURFACE $\mathrm{CMM}_{\mathrm{M}}$, the nominal part surface found on the CMM. The location where the surface would be detected if machining were done without error compensation is of course different from the location if machining were done with error compensation. For the case of machining with error compensation, the actual location of the surface is called

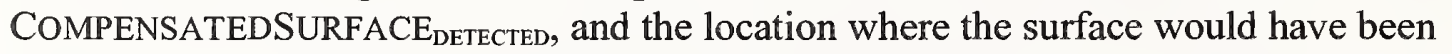

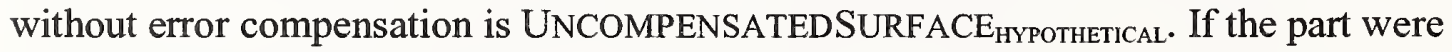
machined without error compensation, the actual location is

UNCOMPENSATEDSURFACE $E_{D E T E C T E D}$, and the location where the surface would have been with error compensation is COMPENSATEDSURFACE HYPOTHETICAL.

Inspection is performed at gauging points predefined on the nominal surface. The actual surface is detected at each gauging point by inspecting the part with a touch-trigger probe either on the machine tool or on a CMM. The nominal and hypothetical surfaces are represented by points where the surface normal vector at the gauging point intersects those surfaces. 

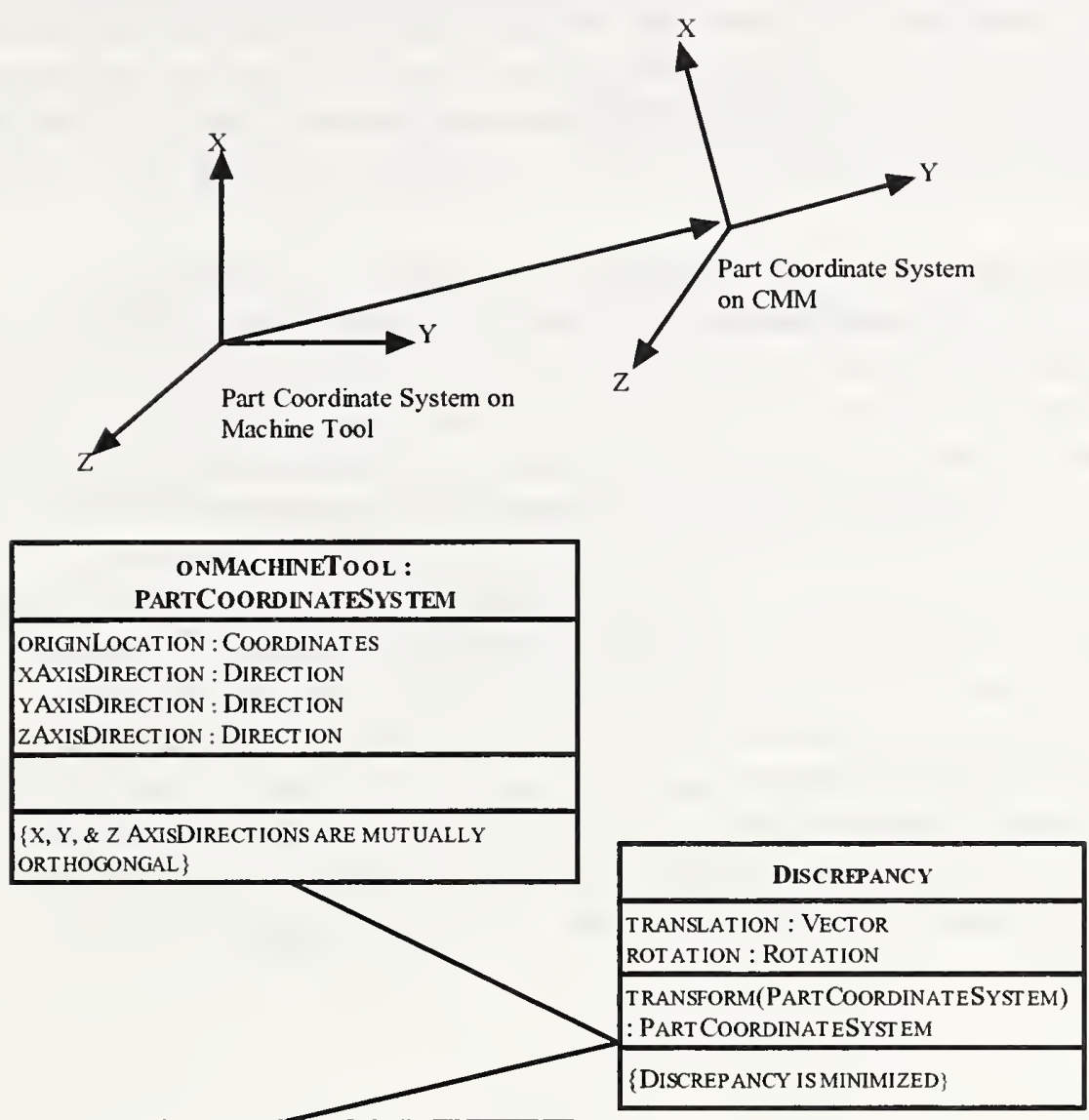

ONCMM : PARTCOORDINATESYSTEM

ORIGINLOCATION : COORDINATES

XAXISDIRECT ION : DIRECT ION

YAXISDIRECTION : DIRECTION

ZAXISDIRECTION : DIRECTION

$\{X, Y, \& Z$ AXISDIRECTIONS ARE MUT UALLY

ORT HOGONGAL

Figure 6. The part coordinate system discrepancy.

Before inspection begins on a CMM, a setup routine is used to define the part coordinate system. Closed-loop machining procedures require an attempt to locate the part coordinate system on the CMM to be as close as possible to the part coordinate system used by the machine tool to fabricate and inspect the part. Figure 6 shows that the determination of the part coordinate system can differ on the machine tool and CMM. A significant variable is operator judgement in finding the part coordinate system. It is assumed in this article that the CMM operator's procedure locates the part coordinate system as accurately as possible. Other factors that may contribute to inaccurate location of the part coordinate also cannot be quantified, and are therefore not considered here. 
The lower part of Figure 6 shows how the part coordinate system discrepancy is modeled in UML. The boxes in the figure show objects. The names of the objects are in the topmost box to the left of the colon and the class name the object is a member of is to the right of the colon. The boxes below the names contain the attributes and operations, respectively. Only the class DISCREPANCY has an operation. The solid lines show links between the objects. As indicated above, the value of the DISCREPANCY should be minimized.

During inspection, when a probe contacts a part surface at a gauging point (approximately), the coordinates recorded are inferred from the same frame of reference used to assume the nominal coordinates for the point. Then, the location of the nominal surface is known with respect to the detected surface. For on-machine inspection of a part, the derived location of the nominal surface at a gauging point, NOMINALSURFACE $\mathrm{MT}_{\mathrm{MT}}$, is determined with respect to the surface detected with the probe controlled by the machine tool. (It will be illustrated later in Figure 14 that this location of NOMINALSURFACE ${ }_{M T}$ must be adjusted for machine tool geometric errors if the surface was machined with machine tool geometric error compensation). For post-process inspection of a part, the location of the nominal surface at a gauging point, NOMINALSURFACE $\mathrm{C}_{\mathrm{CMM}}$, is found based on the determination of the part coordinate system on the CMM. NOMINALSURFACE ${ }_{\mathrm{CMM}}$ is assumed to be the correct, fixed nominal surface, while the location of NOMINALSURFACE ${ }_{\mathrm{MT}}$ depends on the machine tool geometric errors. As explained before, NOMINALSURFACE $\mathrm{MT}_{\mathrm{MT}}$ is a concept used in surface/error diagrams used to help represent machine tool geometric errors in the context of other error components. 


\subsection{Machining Without Error Compensation}
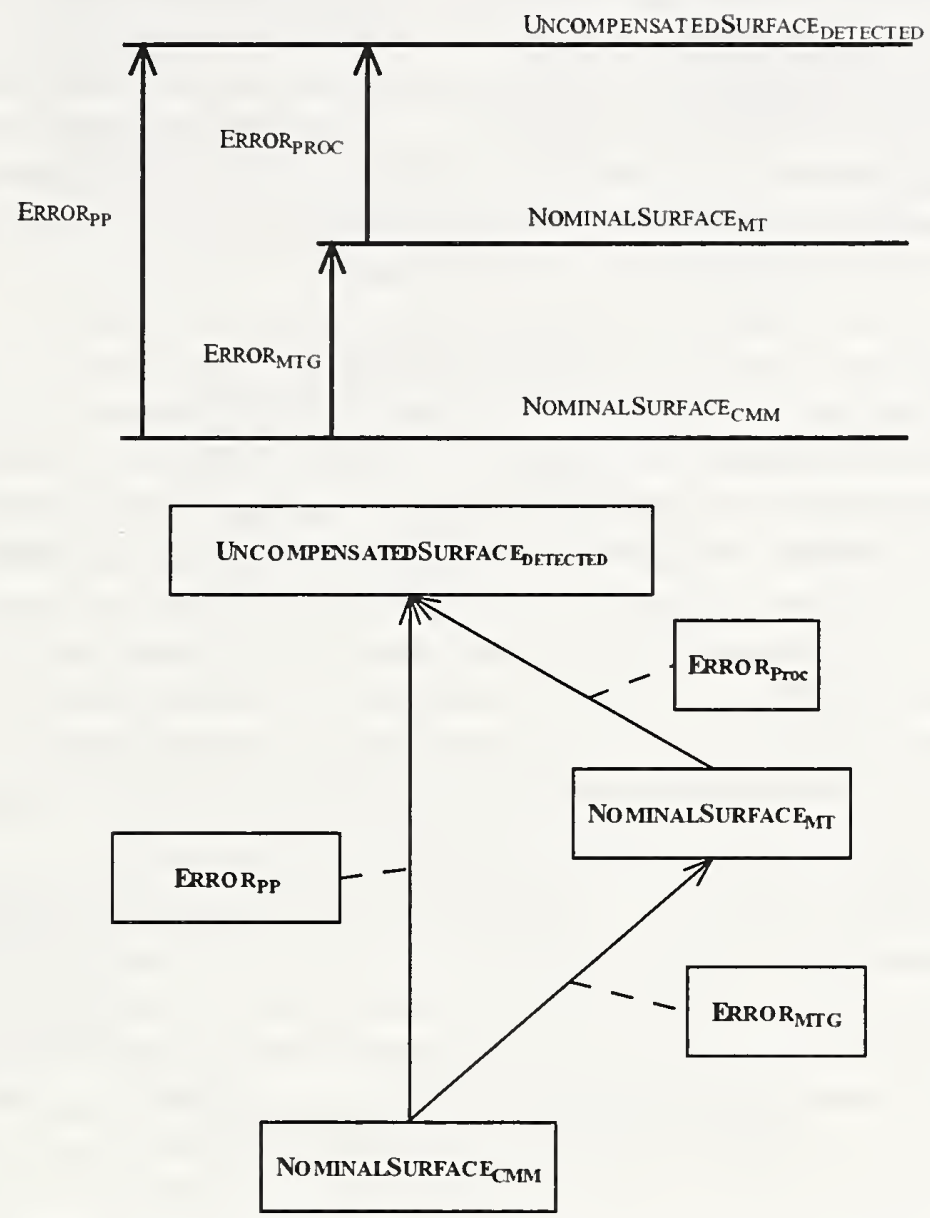

Figure 7. Error components for a part machined without error compensation.

Figure 7 illustrates measurements from both on-machine and post-process inspection of a part fabricated without error compensation. All the implications stated here for the figure are valid regardless of the relative locations of the indicated surfaces. During inspection, a probe detects the surface (labeled UNCOMPENSATEDSURFACE DETECTED $_{\text {) }}$ while attempting to touch a gauging point, and a coordinate is reported. (Only a single coordinate for an axis normal to the part surface is reported. Since all error vectors are defined as normal to the surface at the point, the scenario is one-dimensional.) The two modes of inspection will find different coordinates for the same point. This is because the machine tool geometric error, ERROR ${ }_{\mathrm{MTG}}$, is not detected by on-machine inspection of a part surface that was machined without error compensation, ${ }^{6}$ but is detected by post-process

\footnotetext{
${ }^{6}$ This is an approximation that may also be assumed under certain conditions for a surface machined with error compensation. There are two theoretical cases in which process errors may be computed from the results of on-machine inspection with the complete exclusion of any machine tool geometric error. In each
} 
inspection. The nominal dimension for the gauging point is known in advance in (approximately) the same reference frame as the coordinate reported at probe contact. For on-machine inspection, this locates the NOMINALSURFACE ${ }_{M T}$ with respect to

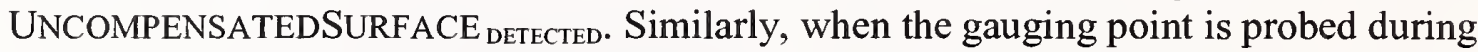
post-process inspection, NOMINALSURFACE ${ }_{\text {CMM }}$ is located with respect to UNCOMPENSATEDSURFACE DETECTED. $_{\text {ERROR }}$ MTG is the difference between the location of NOMINALSURFACE $\mathrm{M}_{\mathrm{MT}}$ and NOMINALSURFACE ${ }_{\mathrm{CMM}}$. This is because the disparity between the two measuring devices (the machine tool and the CMM), and thus between the two derived locations of the nominal part surface at the gauging point, is assumed to be due to the thermally-influenced geometric errors in the machine tool. There are two exceptions to this statement. First, if a portion of the machine tool geometric error is compensated using a GT model, then NOMINALSURFACE $\mathrm{M}_{\mathrm{MT}}$ and NOMINALSURFACE $\mathrm{CMM}_{\mathrm{M}}$ will be

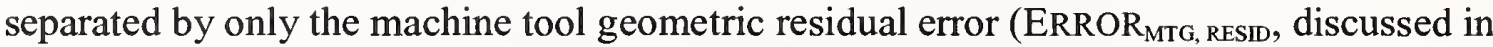

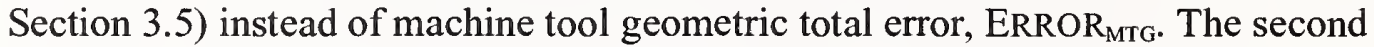
exception is that a portion of the process error can be accidentally included in the computation of the machine tool geometric residual error. An inconsistent GT model may calculate an error at a point for machining temperatures that does not correctly correspond to the error calculated for the same point at inspection temperatures. (This problem is explained further in Footnote 6 on page 13.) For the derived nominal surface relationships presented here to be valid, any accidentally included portion of process error is assumed to be small compared to the machine tool geometric residual error.

ERROR $_{\mathrm{PROC}}$, the normal vector from the NOMINALSURFACE $\mathrm{MT}_{\mathrm{MT}}$ to the

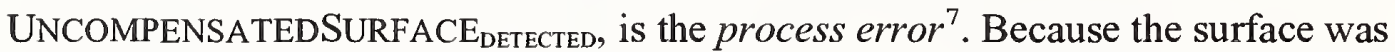
machined without error compensation in this case, ERROR PROC $_{\text {is }}$ equal to ERROR PROC, RESID (not indicated), the process residual error, explained in Section 3.5. ERROR $R_{\mathrm{PP}}$, the normal vector from the NOMINALSURFACE ${ }_{\text {CMM }}$ to the UNCOMPENSATEDSURFACE DETECTED, $_{\text {, is }}$ the error determined by post-process inspection. ERROR PROC $_{\text {and ERROR }}$ MTG are independent of one another in both magnitude and sign. The CMM is assumed to measure the total error, ERROR $\mathrm{pp}$.

case the GT model is used both to compensate machine tool geometric errors during machining, and to subtract machine tool geometric errors from the coordinates measured during inspection. (Error compensation is not in effect during inspection.) In the first case, the lengths of the probe and cutting tool are the same, and the thermal condition of the machine tool is the same during inspection as it was during machining. In the second case, the GT model will compute an error compensation vector that will leave the same residual error for any point and any machine tool temperatures. In a real situation, the confounding of computed process errors with machine tool geometric residual errors will depend on how closely the situation matches either of these two cases.

\footnotetext{
${ }^{7}$ Machining process errors are attributable to such causes as length, wear, or deflection of the tool; or location, clamping, or deflection of the workpiece.
} 


\subsection{Accounting for Machine Tool Geometric Errors}

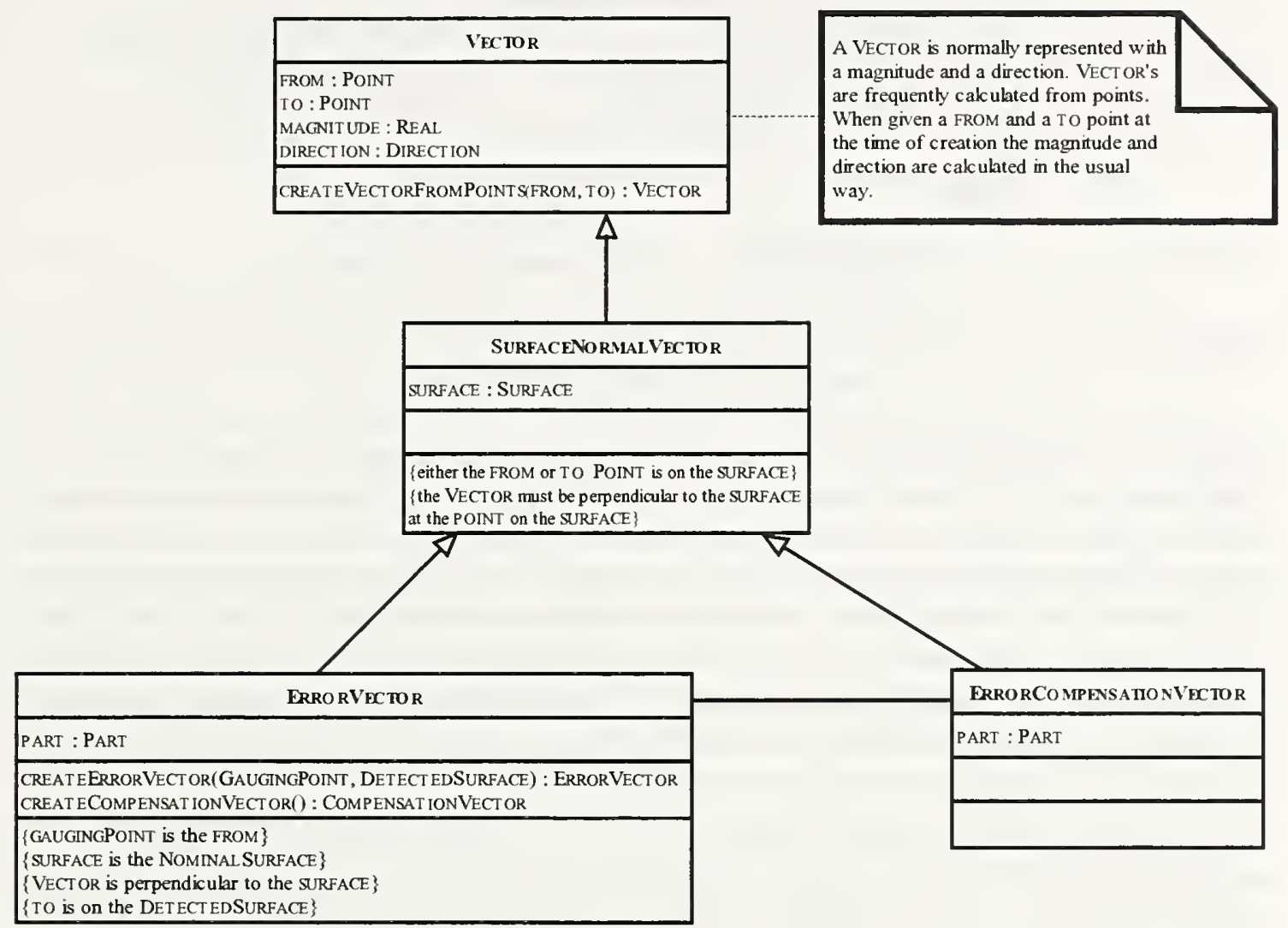

Figure 8. Basic vector relationships.

To compensate an anticipated error, the position of the cutting tool must be adjusted by adding the components of the error compensation vector to the machine position coordinates. Figure 8, above, shows the relationship between ERRORVECTORs and ERRORCOMPENSATIONVECTORS. The ideal ERRORCOMPENSATIONVECTOR is the negative of the ERRORVECTOR. This inverse association is ideal, but is only approximate in practice.

A GT model of the machine tool calculates the error compensation vector for a specified cutter location for a specified set of machine temperatures. An additional adjustment for process errors is discussed later. This is shown in Figure 5 in Section 2, by the activity Supply GT Corrections for Coordinates. 


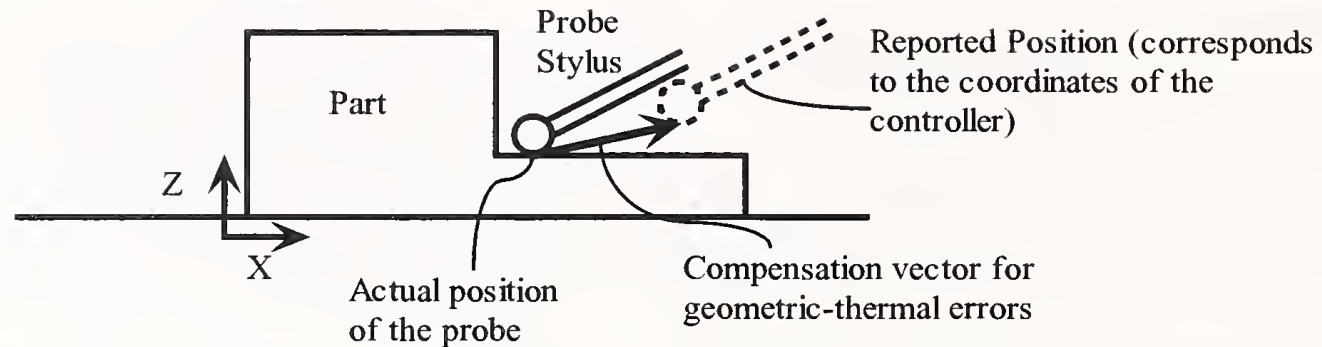

Figure 9. The probe position reported by the machine tool controller is inaccurate due to machine tool geometric errors.

To find the nominal surface at a point on the part, the coordinates measured on the detected surface must be adjusted by adding the components of the error compensation vector to them. Again, the error compensation vector is calculated with the GT model, this time for the detected surface coordinates at the probing temperatures. Although the GT model will not be perfect, it is the best available source for inferring GT deviations for correcting coordinates found by inspection. The adjustment in coordinates is required because, when the machine position is correct (known because the probe has contacted the part), the wrong coordinates are reported due to machine tool geometric errors. The rationale for the adjustment is illustrated in Figure 2.

The on-machine probe moves to contact a part surface. The machine tool controller reports the position COORDS CONTROLLER $^{8}$ (in $\mathrm{X}$ and $\mathrm{Z}$ coordinates, in this two-dimensional example) when the probe is triggered. The current set of machine temperatures is represented by $\mathrm{T}_{\mathrm{PROBING}}$. The GT model determines that, for $\mathrm{T}_{\mathrm{PROBING}}$ and COORDS $_{\text {CONTROLLER }}$, an error compensation vector COMP MTG $_{\text {would adjust the reported }}$

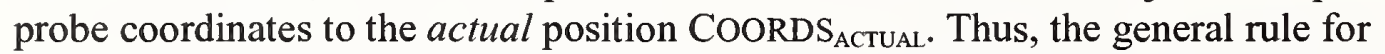
interpreting coordinates reported by the controller during probing is to subtract the error compensation vector determined for the coordinates, evaluated at the probing temperatures.

$$
\text { COORDS }_{\text {ACtUAL }}=\text { COORDS }_{\text {CONTROLLER }}-\text { COMP }_{\text {MTG }}\left(T_{\text {PROBING }}, \text { COORDS }_{\text {CONTROLLER }}\right)
$$

This equation gives the actual machine position when the probe trips, as a function of the current machine temperatures and the current position reported by the controller.

\footnotetext{
${ }^{8}$ The transformation from machine coordinates with respect to the machine origin, to part coordinates with respect to the part origin, is irrelevant here, and is therefore not included in the discussion.
} 


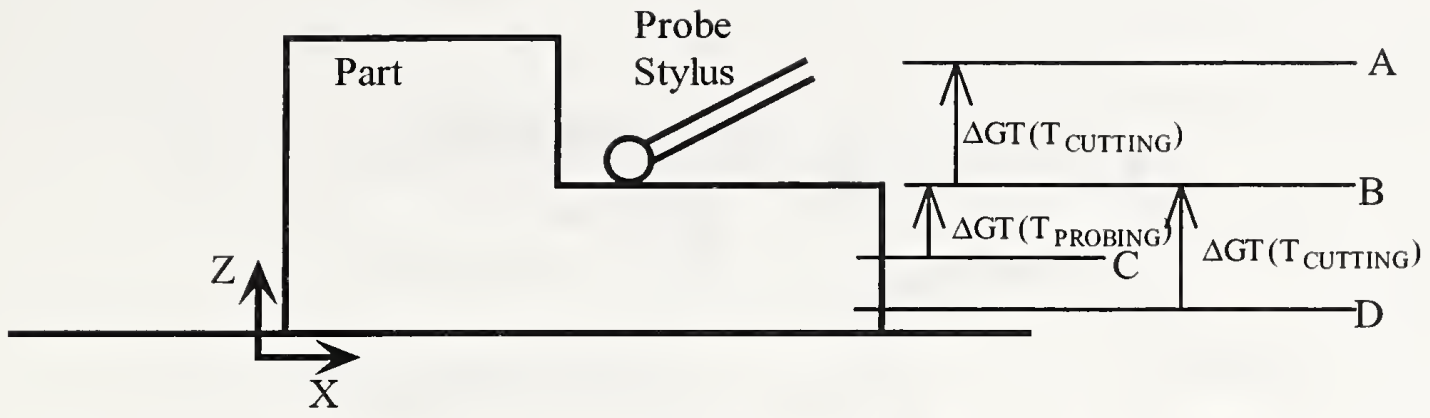

Figure 10. The GT model is used to compute coordinate adjustments to account for machine tool geometric errors at cutting temperatures and probing temperatures.

Since calculations for machine tool geometric error compensation must apply the GT model at cutting (machining) temperatures as well as probing temperatures, several sets of coordinates are involved for each gauging point. Figure 10 is a two-dimensional illustration of a probe stylus making contact with a part surface. In addition to the actual location of the surface, denoted by $\mathrm{B}$, the figure shows examples of other hypothetical locations that could be involved in the effort to determine the $\mathrm{Z}$ coordinate of $\mathrm{B}$ (at some given $\mathrm{X}$ coordinate). The variables are the set of machine temperatures at which the part was cut, the set of machine temperatures at which the part is probed, the coordinate reported by the machine tool controller for the contact point of the probe or cutting tool position, and the GT model. First, consider that if machining was done without machine tool geometric error compensation while the machine temperatures were $T_{\text {CUTTING }}$, the controller would have reported the desired dimension B while machining, but the surface may have been cut to $\mathrm{D}$ due to machine tool geometric errors. If machining were done with machine tool geometric error compensation (assuming a perfect GT model) while the machine temperatures were $T_{\text {CUTrING }}$, the controller would have to report $A$ to cut the surface to the desired dimension B. Suppose probing is done at machine temperatures $\mathrm{T}_{\text {PROBING}}$, and the controller reports $\mathrm{C}$. (Probing is always performed without error compensation in effect.) In this case, the actual surface coordinate $\mathrm{B}$ can be calculated by using the GT model to adjust $\mathrm{C}$ at $\mathrm{T}_{\mathrm{PROBING}}$. These are the kinds of considerations that need to be made for machine tool geometric error compensation. 


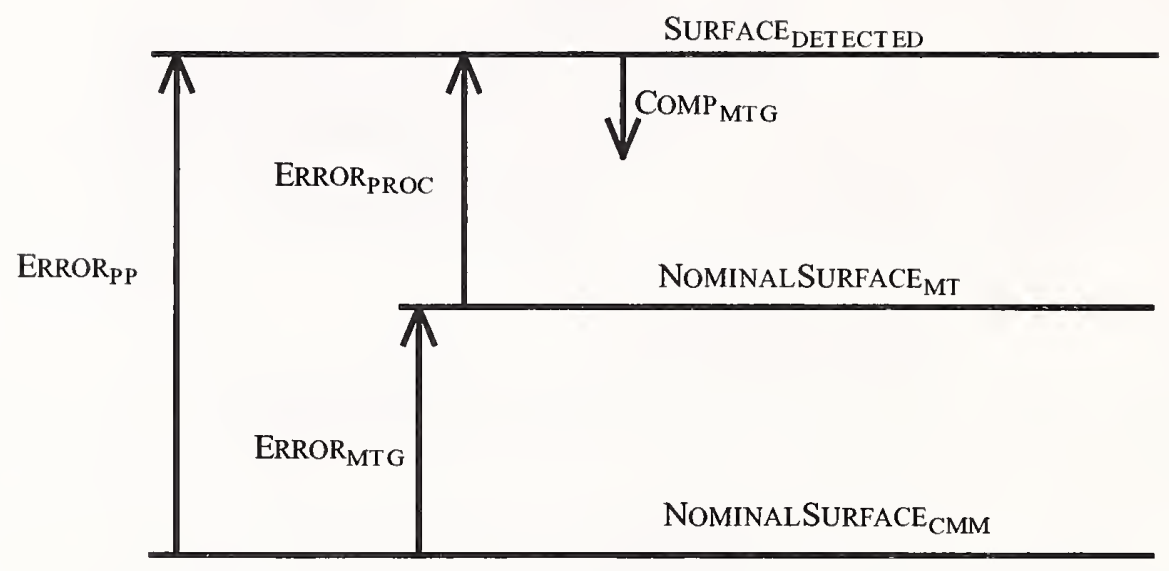

Figure 11. The placement of an error compensation vector in a conceptual picture can be misleading.

Since $\mathrm{COMP}_{\mathrm{MTg}}$ is a vector, it may be considered to be anywhere in the range indicated by ERROR $_{\mathrm{PP}}$ in Figure 11. Superficially observing the results of process-intermittent inspection, COMP ${ }_{\mathrm{MTG}}$ may seem to offset ERROR $\mathrm{PROC}_{\mathrm{P}}$. To caution the reader, Figure 11 illustrates this misleading interpretation. The implied effect is that the detected surface would be moved to the head of the vector COMP ${ }_{\mathrm{MTG}}$. Actually, however, the machine is accurate enough to cut to NOMINALSURFACE ${ }_{M T}$, if not for process errors. Therefore, $\mathrm{COMP}_{\mathrm{MTG}}$ should be considered to affect only ERROR ${ }_{\mathrm{MTG}}$, as shown later in Figure 14. 


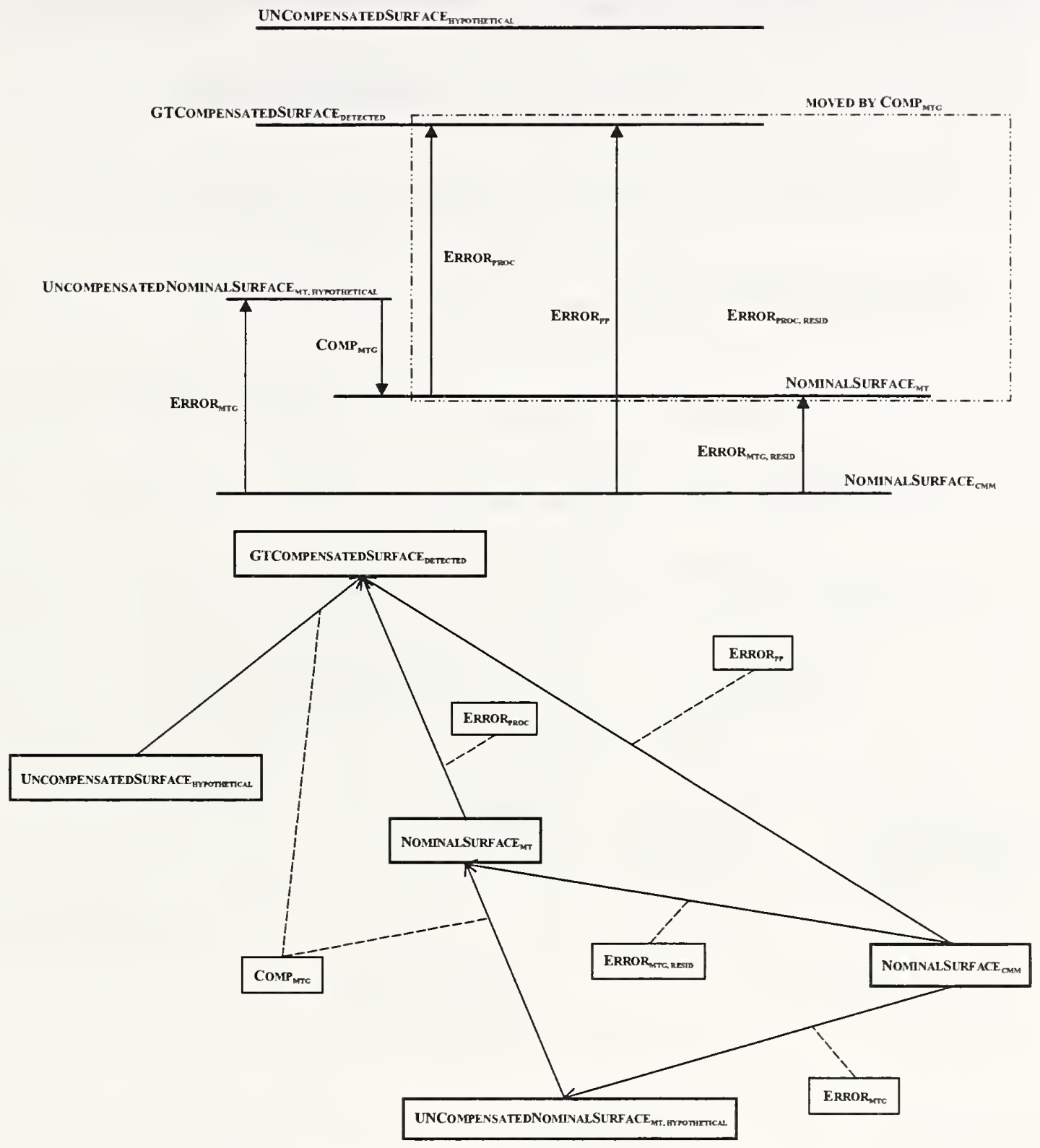

Figure 12. Compensation of machine tool geometric errors.

Figure 12 shows both a UML diagram and a surface/error diagram of the results of machining while compensating only machine tool geometric errors. The surfaces enclosed in the dotted-line box labeled MOVED BY COMP ${ }_{\text {MTG }}$ have moved together because of COMP ${ }_{\text {MTG. }}$. GTCOMPENSATEDSURFACE DECTECTED $_{\text {moved from }}$ UNCOMPENSATEDSURFACE HYPOTHETICAL as NOMINALSURFACE MT $_{\text {moved from }}$ UNCOMPENSATEDNOMINALSURFACE $E_{\mathrm{MT} \text {, HYPOTHETICAL }}$. COMP ${ }_{\text {MTG }}$ compensated part of ERROR $_{M T G}$, with ERROR ${ }_{M T G, \text { RESID }}$ remaining. The post-process error, ERROR PP $_{\text {, was }}$ also reduced by COMP ${ }_{\mathrm{MTG}}$. The discrepancy in the nominal surface locations continues to 


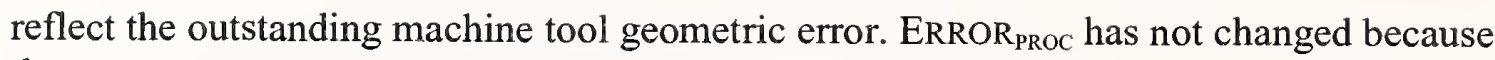
there was no process error compensation. 


\subsection{Combined Error Compensation}

UNCOMPENSATEDSURFACE

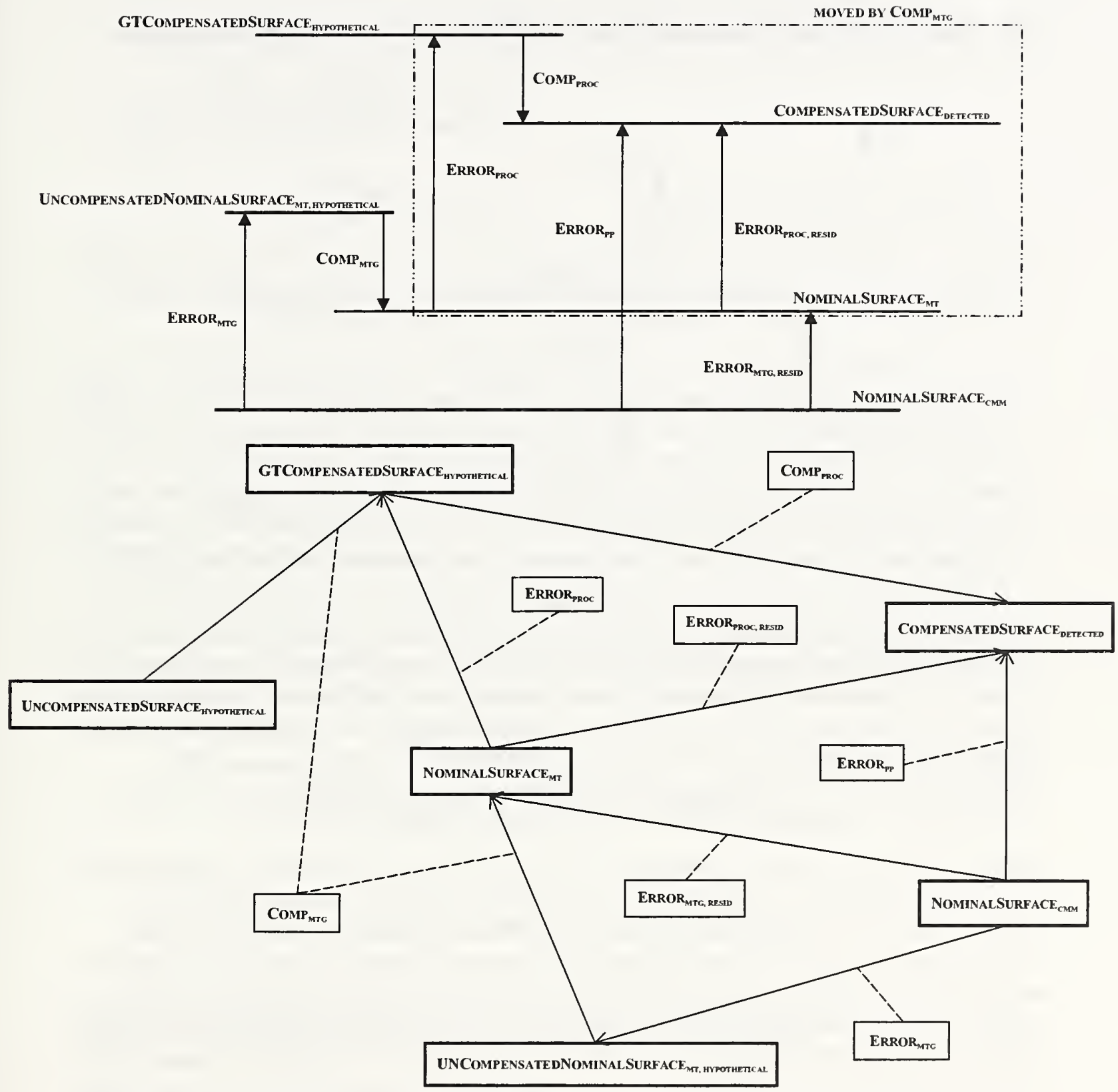

Figure 13. Combined compensation of both machine tool geometric errors and process errors.

Figure 13 shows the result of compensating both machine tool geometric errors and process errors. The surface/error diagram is the same as Figure 12 outside the dotted-line 
box labeled MOVED BY COMP ${ }_{\mathrm{MTG}}$, indicating machine tool geometric error compensation. But the differences within the box show the effects of process error compensation. COMP $_{\text {PROC }}$ has moved COMPENSATEDSURFACE $E_{\text {DETECTED }}$ from the GTCOMPENSATEDSURFACE HYPOTHETICAL $_{\text {position. COMP }}$ PROC $_{\text {compensated part of ERROR }}$ PROC, with ERROR ${ }_{\mathrm{PROC}}$, RESD remaining. The post-process error, ERROR ${ }_{\mathrm{PP}}$, was also reduced by COMP $_{\text {PROC }}$.

\subsection{Distinguishing Process Errors and Machine Tool Geometric Errors}

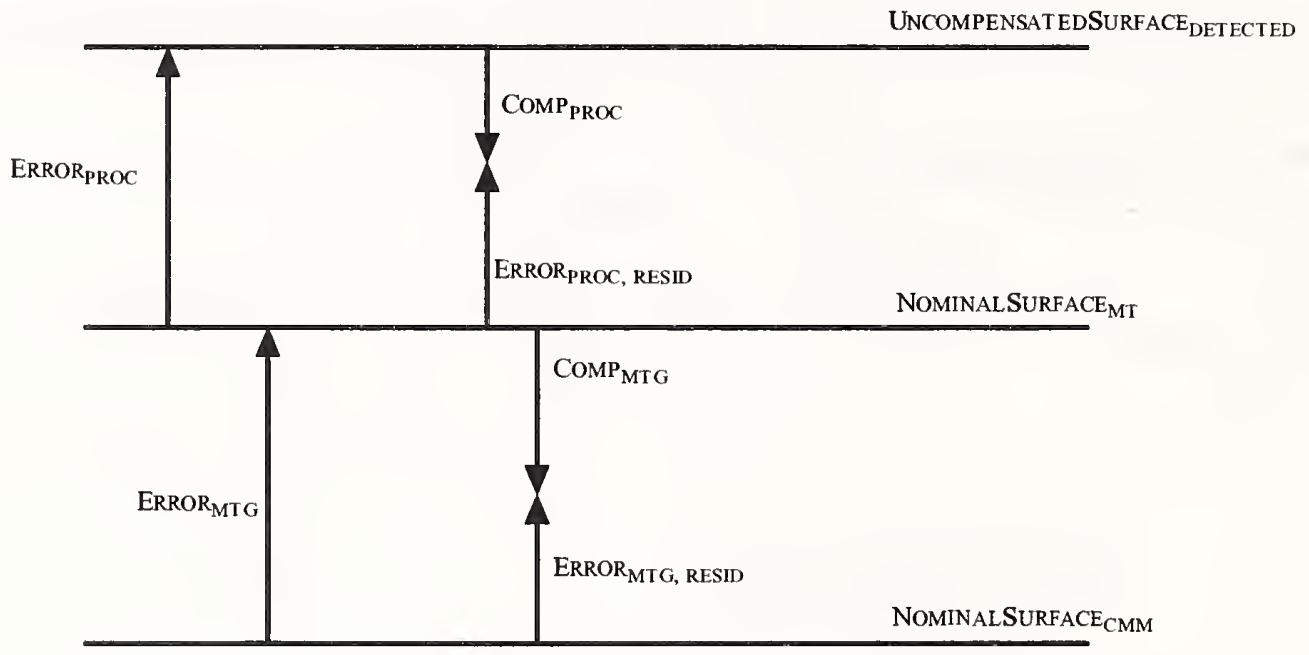

Figure 14. Residual errors may remain after error compensation has been applied.

To machine with error compensation, the tool is to be offset by vectors with equal magnitude as, but with opposite sign to, the predicted errors. The offset vector calculated by the GT model to reduce ERROR ${ }_{M T G}$ is denoted as COMP $\mathrm{MTG}_{\mathrm{MT}}$. COMP $_{\mathrm{PROC}}$ is the vector to compensate ERROR ProC. $_{\text {. Figure } 14}$ shows the directions the error compensation vectors, if applied during machining, would move UNCOMPENSATEDSURFACE DETECTED $_{\text {and }}$

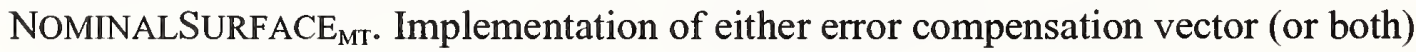
would bring the detected surface closer to the actual nominal dimension.

Placing COMP $_{\mathrm{MTG}}$ as shown in Figure 14 clearly illustrates the concept of machine tool geometric residual error, ERROR MTG, RESID $_{\text {: the portion of ERROR }}$ MTG remaining after $\mathrm{COMP}_{\mathrm{MTG}}$ has been applied. The GT model is to be periodically refined to calculate COMP $_{\text {MTG values that will reduce ERROR }}$ MTG, RESI more effectively. Similarly, it may be seen in Figure 14 that a portion of ERROR ${ }_{\mathrm{PROC}}$ may remain after $\mathrm{COMP}_{\mathrm{PROC}}$ has been

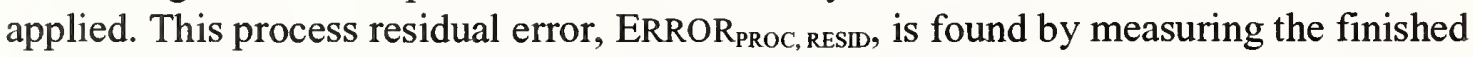
part on the machine tool, adjusting the coordinates with the GT model for $\mathrm{T}_{\text {PROBING}}$, and then calculating the error. (This statement is reasonable as long as any portion of process residual error accidentally included in the computation of the machine tool geometric residual error is assumed to be comparatively small. This is explained in Section 3.2.) ERROR $_{\text {PROC, RESID }}$ may be reduced on the next part by calculating a refined value for COMP ${ }_{\text {PROC }}$. 
UNCOMPENSAT EDSURFACE ${ }_{\text {HYPOT HET ICAL }}$

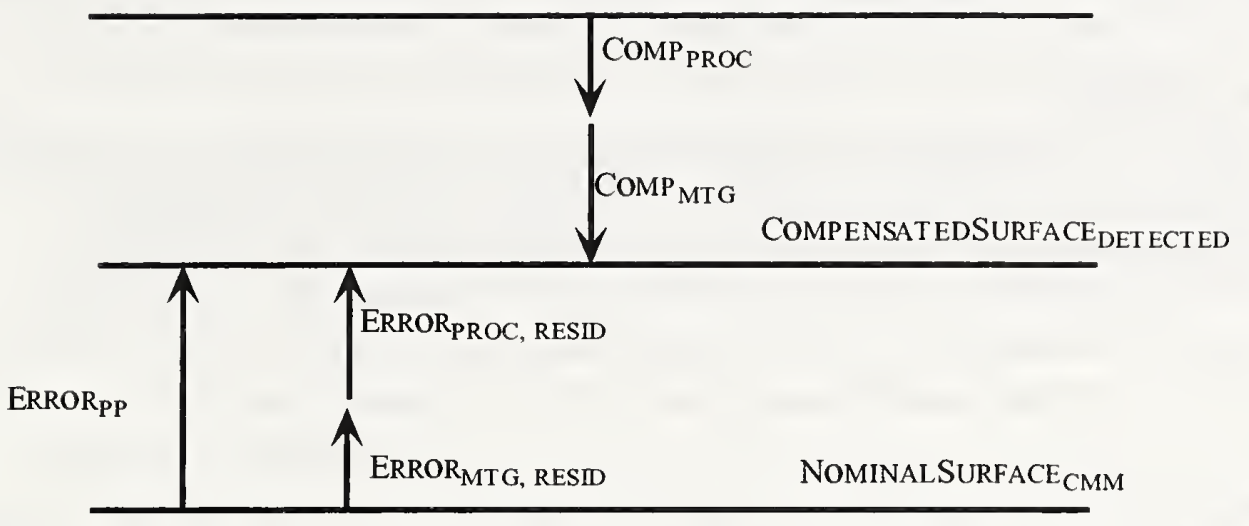

Figure 15. The error compensation vectors may be arranged and placed in a conceptual picture to show how error compensation changed the position of the part surface.

Figure 15 illustrates a situation useful for calculating the improvement needed in COMP $_{\text {MTG }}$. The vectors COMP ${ }_{\mathrm{PROC}}$ and $\mathrm{COMP}_{\mathrm{MTG}}$ are positioned to show how much they will cause the location of the surface to move. In this case, $\mathrm{COMP}_{\mathrm{MTG}}$ is calculated for $\mathrm{T}_{\text {CUTTING }}$, the set of machine temperatures at the time the part was machined. If both modes of error compensation (with the possibility of zero compensation for either) have been implemented, the detected surface will be displaced from where it would otherwise be (at UNCOMPENSATEDSURFACE HYPOTHETICAL $_{\text {) by a vector equal to COMP }}$ PROC + COMP $_{\text {MTG }}$.

Ideally, COMP MTG $_{\text {M }}\left(T_{\text {CUTTING }}\right)=-$ ERROR $_{\text {MTG }}$, and COMP PROC $=-$ ERROR $_{\text {PROC }}$. In this ideal case, COMPENSATEDSURFACE DETECTED $_{\text {Would be located at NOMINALSURFACE }}$ CMM because there would be no residual errors, and ERROR ${ }_{P P}$ would equal zero. In practice, however, errors ERROR MTG, RESID $_{\text {and ERROR }}$ PROC, RESID remain after machining with error compensation. It is seen from Figure 14 that

$$
\operatorname{COMP}_{\text {MTG }}\left(T_{\text {CUTTING }}\right)=- \text { ERROR }_{\text {MTG }}+\text { ERROR }_{\text {MTG, RESID }}
$$

and

$$
\mathrm{COMP}_{\mathrm{PROC}}=-\mathrm{ERROR}_{\mathrm{PROC}}+\mathrm{ERROR}_{\mathrm{PROC}, \mathrm{RESID}}
$$

But with the vectors rearranged in Figure 15, the total residual error may be seen. This sum of the uncompensated errors is found by post-process inspection.

$$
\mathrm{ERROR}_{\mathrm{PP}}=\mathrm{ERROR}_{\mathrm{MTG}, \mathrm{RESID}}+\mathrm{ERROR}_{\mathrm{PROC}, \mathrm{RESID}}
$$

Residual error may then be computed.

$$
\text { ERROR }_{\text {MTG, RESID }}=\text { ERROR }_{\mathrm{PP}}-\mathrm{ERROR}_{\mathrm{PROC}, \mathrm{RESID}}
$$


Statistically derived values of ERROR ${ }_{\text {MTG, RESID }}$ for many points on many parts are used in a post-process analysis to improve the GT model to compute more accurate values of COMP $_{\mathrm{MTG}}$.

\section{Conclusions}

A developer of error compensation routines for closed-loop machining systems must understand many aspects of part errors. However, correct treatment of the error components requires a clear understanding of data relationships that are not readily apparent. Since some of the concepts involved are more complex than they may seem without rigorous consideration, incorrect assumptions may be easily made. Problems in an improperly formulated error compensation routine are hard to identify.

Therefore, this report has attempted to help prevent such problems by clarifying the relationships between several of the key quantities involved in closed-loop machining error compensation. The use of software engineering modeling techniques has provided a breakdown into the data structures, represented as classes, that a closed-loop system will need to have to work. The classes that have been explained here should help with interpreting inspection data, decomposing errors into components, distinguishing the contributions of error compensation adjustments, and locating nominal surfaces for error computations.

One unique perspective used is the error/surface diagrams. For one gauging point at a time, these diagrams allow the machine tool geometric error to be viewed in the context of the other error components to see the effects of error compensation. This is facilitated by the concept of a derived location for the nominal surface based on the on-machine error. With increasingly effective compensation of machine tool geometric errors, this derived nominal surface would tend to converge with the nominal part surface found on the $\mathrm{CMM}$, indicating the reduction of error.

Another useful concept introduced here is the hypothetical uncompensated surface. Inspection detects the surface at this location if the part is machined without error compensation. The diagrams show how machining with error compensation will produce a detected surface that is closer to the nominal location.

Sorting, understanding and analyzing error components to develop error compensation algorithms are very complex. The insight and methods provided by this document are adaptable many implementations of closed-loop machining, and therefore should be of great value in helping a software engineer understand the elements involved in developing such a system. 


\section{References}

[Bandy 1996] PIECS-A Software Program for Machine Tool Process-Intermittent Error Compensation. Herbert T. Bandy and David E. Gilsinn. NISTIR 5797, National Institute of Standards and Technology, Gaithersburg, MD.

[Bandy 2001] A Methodology for Compensating Errors Detected by ProcessIntermittent Inspection. Herbert T. Bandy, M. Alkan Donmez, David E. Gilsinn, Chin San Han, Michael D. Kennedy, Alice V. Ling, Neil D. Wilkin, and Kenneth W. Yee. NISTIR 6811, National Institute of Standards and Technology, Gaithersburg, MD.

[Booch 1993] Object-Oriented Analysis and Design With. Grady Booch. AddisonWesley, Boston, MA.

[Booch 1998] The Unified Modeling Language User Guide. Grady Booch, James Rumbaugh, and Ivar Jacobson. Addison-Wesley, Boston, MA.

[Donmez 1991] Progress Report of the Quality in Automation Project for FY90. M. Alkan Donmez, ed. NISTIR 4563, National Institute of Standards and Technology, Gaithersburg, MD.

[Donmez 1986] A General Methodology for Machine Tool Accuracy Enhancement by Error Compensation. M. Alkan Donmez, Donald S. Blomquist, Robert J. Hocken, C. Richard Liu, Moshe M. Barash. Precision Engineering, 8(4), 187196.

[ISO 1993] International Vocabulary of Basic and General Terms in Metrology

(VIM). International Organization for Standardization (ISO), Geneva, Switzerland.

[Jacobson 1992] Object-Oriented Software Engineering: A Use Case Driven

Approach. Ivar Jacobson. Addison Wesley, Boston MA.

[Meyer 1997] Object-Oriented Software Construction, (with CD-ROM). Bertrand

Meyer. Prentice Hall, Upper Saddle River, NJ.

[OMG 2001] OMG Unified Modeling Language Specification. Object Management Group. OMG, Needham, MA.

[Rumbaugh 1990] Object-Oriented Modeling and Design. James Rumbaugh, William Premerlani, Michael Blaha, William Lorensen, and Frederick Eddy. Prentice Hall, Upper Saddle River, NJ.

[Rumbaugh 1998] The Unified Modeling Language Reference Manual (UML). James Rumbaugh, Ivar Jacobson, and Grady Booch. Addison Wesley, Boston, MA. 


\section{Appendix I: $\quad$ UML Conventions Used in This Article}

The Unified Modeling Language, UML, is a visual language for expressing the architecture of software systems. The language has many parts. Each part is used for describing a different aspect of the system. In this paper we used two different types of diagrams, activity diagrams and class diagrams.

One of the roles of an activity diagram is to capture the context within which a software system is to function. This is the role that the activity model in section 2 of the paper is used for.

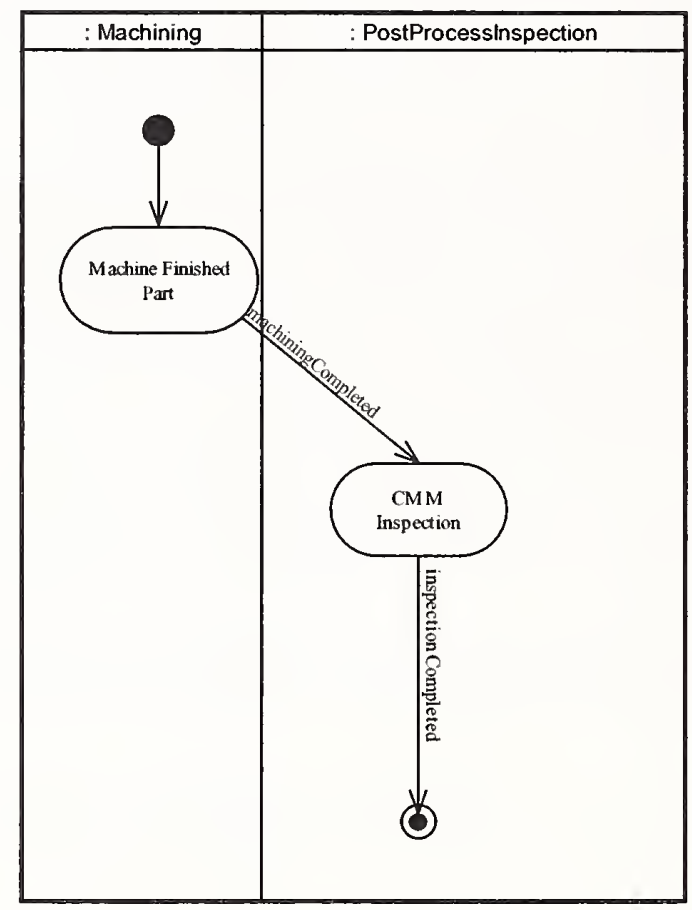

Figure 16. Activity diagram example.

Figure 16 is a simple example of how machining and inspection might be expressed using an activity diagram. The column headers MACHINING and POSTPROCESSINSPECTION are the names of classes. A class is a collection of objects. The paper uses the convention of small and large capital letters as class names. The papers follows the UML convention that the first letter of a class name is capitalized and the first letter of each new word is capitalized with the words run together. The colon to the left of the class names is UML notation for class instance or object. Because there is only one instance of each class in the diagram object names are unnecessary and objects in the diagram are referred to by their class name.

A column in Figure 16 is UML notation for swimlanes. A swimlane is used to associate activities with classes. Thus there is one column for each class. The solid circle is UML notation for a starting state, and the solid circle within a larger clear circle is UML notation for an end state. The ovals containing the words Machine Finished Part and CMM Inspection are activities. In the diagram the paper uses UML notation of 
capitalizing each word and separating each word by a space. The activity Machine Finished Part is associated with the class MACHINING and the activity CMM Inspection is associated with the class POSTPROCESSINSPECTION. Activity names that appear within the paper are italicized to distinguish them from the text of the paper.

The arrows in Figure 16 are referred to as events. When an event occurs, control is transferred from one activity to another. The events may have names such as machiningCompleted and inspectionCompleted. The text of the paper uses the convention of using small and large capital letters for event names. The diagrams use the UML conventions of making the first letter of an event name a small letter and after that capitalizing the letter of each new word and running the words together.

With that background, Figure 16 shows that at the start a part is machined by the activity Machine Finished Part until the event machiningCompleted. Then the part is inspected by the activity CMM Inspection until the event inspectionCompleted. When the last activity is completed in the diagram the activity described by the diagram halts.

The diagram in section 2 is much more complex. The diagram shows multiple activities associated with a class. The diagram also shows multiple events originating from the same activity. Control will pass to the activity for the event that occurs. Only one event may occur at a time in the diagrams we are using. Finally the diagram in section 2 shows that control may loop between multiple activities.

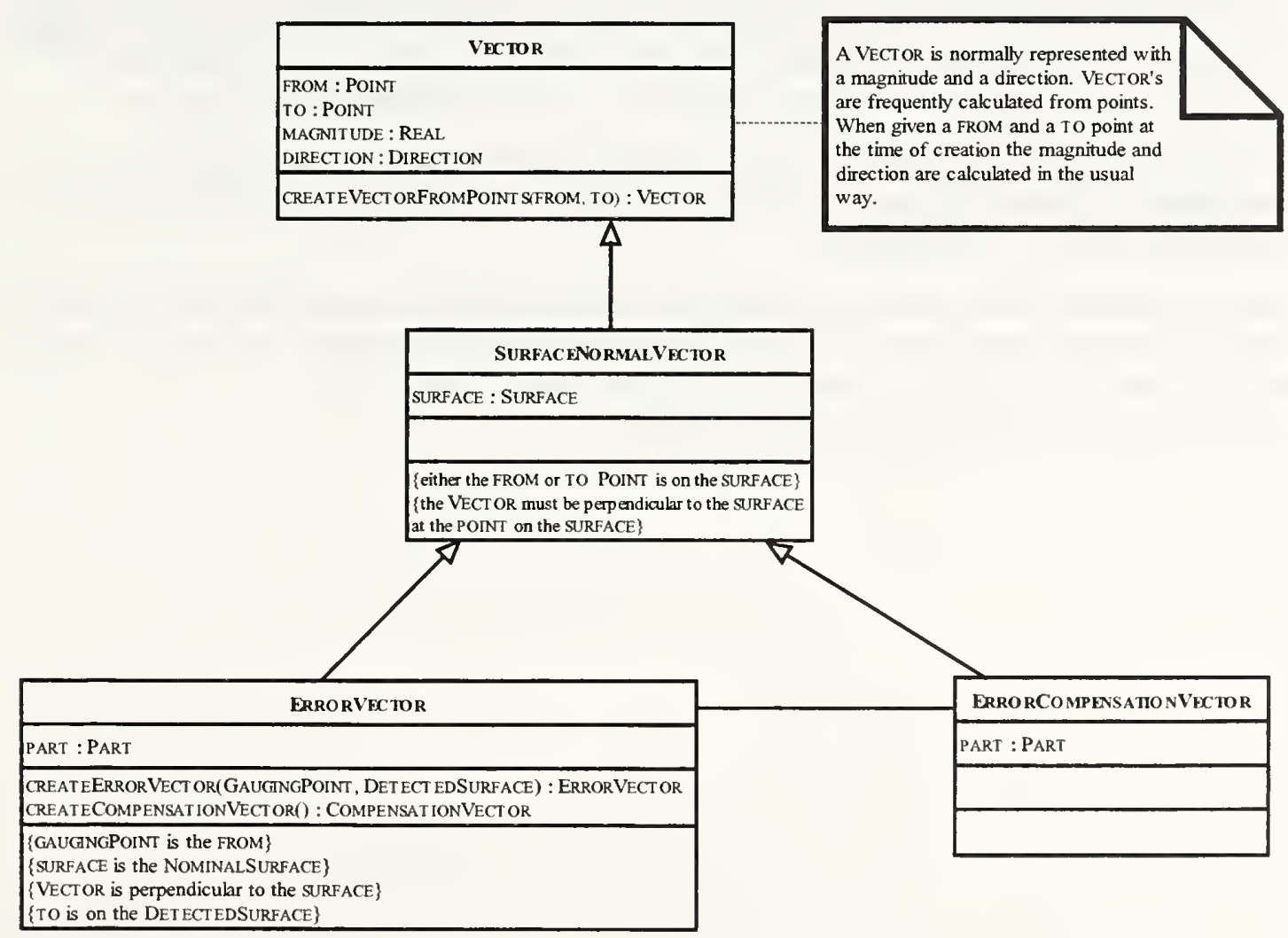

Figure 17. Class diagram example. 
Figure 17 is an example of a class diagram used in the body of the paper. A class is a collection of objects. The box on the upper right hand side with corner folded over is UML notation for a note. The note contains additional information about the UML notation that the note is connected to with the dotted line. In this example the note contains additional information about the class VECTOR.

The class diagram describes the classes VeCTOR, SuRfaceNormalVector, ERRORVECTOR, and to a lesser extent COMPENSATIONVECTOR. The paper uses the convention of small and large capital letters as class names. The paper follows the UML convention that the first letter of a class name is capitalized and the first letter of each new word is capitalized with the words run together.

The name of the class is at the top of each box. There may be zero or up to four divisions below the name of the class. The first division below the class names contains the class's attributes. The second contains the class's operations and the third, the class's constraints. The diagram does not have to show anything other than the name. There is no necessity for the diagram to show all of the attributes, operations or constraints. For example there are operations and constraints obviously not shown for the class COMPENSATIONVECTOR in Figure 17.

Figure 17 shows that the class VECTOR has the attributes FROM, TO, MAGNITUDE, and DIRECTION. Attribute names are done in caps and follow the UML conventions that the first letter is small, words are run together, and the first letter of each run-together word is capitalized. Each attribute has a type that is to the right of the colon. A type is the name of a class and follows the conventions for class names described earlier. The class VECTOR has one operation with two arguments. It does not have any constraints.

The classes SURFACENORMALVECTOR and ERRORVECTOR have constraints. The constraints, properties that always hold true, appear in the bottom box. Each constraint is enclosed between " \{\} " brackets.

The open headed arrows show a generalization relationship. Thus all ERRORVECTORs and COMPENSATIONVECTORS are SURFACENORMALVECTORs. All SURFACENORMALVECTORS are VECTORs. The solid line connecting the class ERRORVECTOR to COMPENSATIONVECTOR shows an association. 


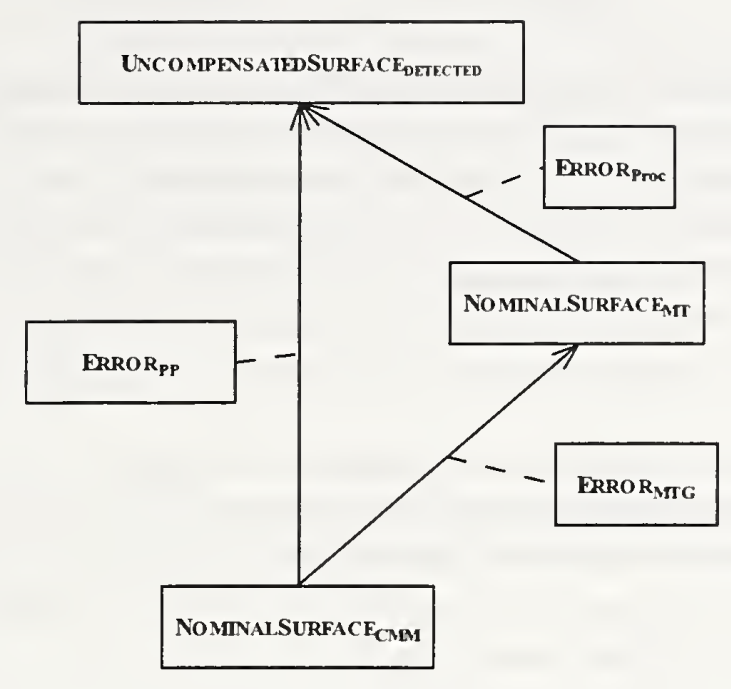

Figure 18. Second class diagram example.

Figure 18 shows associations represented by solid arrows. Each association has a class linked to it via a dashed line and that class is the type of the association. When the type of the association is a VECTOR (ERROR ${ }_{\mathrm{PROC}}$, ERROR MTG $_{\text {, }}$, and ERROR FP $_{\mathrm{P}}$ in the figure above are of type VECTOR) the paper uses the convention that the direction of the association indicates the direction of the VECTOR. 


\section{Appendix II: Glossary}

All coordinates in the following definitions are with respect to the part coordinate system, and refer to the point where either the probe or the cutting tool contacts the part. This is true even for terms referring to the machine tool controller. Although the coordinates known to the machine tool controller are the machine axis positions in terms of the machine coordinate system, this discussion implies transformation to the point of contact, expressed in the part coordinate system. Since none of the analyses presented here deal with measurement inaccuracies, accurate coordinate transformations are assumed.

Note also that the part error relationships studied in this paper are considered at a single point at a time - usually a gauging point, a target for inspection. The location of a part surface at a gauging point is the intersection of the surface with the surface normal vector at the gauging point. (See Figure 1.) Therefore, the "surfaces" defined here are known only as locations on the surface normal vector.

$\mathrm{COMP}_{\mathrm{MTG}}$ : This is the machine tool geometric error compensation vector. It is the vector from a location on the part that the controller reports incorrectly due to geometric-thermal

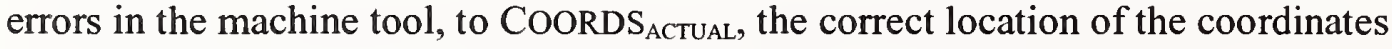
reported by the controller, as computed by the geometric-thermal model.

COMP $_{\mathrm{PROC}}$ : This is the process error compensation vector. It is the correction calculated and applied using the Process-Intermittent Error Compensation Software [Bandy 1996] to offset the process error, ERROR PROC $_{\text {. }}$

COMPENSATEDSURFACE: At any specified point on the part, the location of the part surface if fabrication included retrofitted automated procedures that attempt to compensate process errors, machine tool geometric errors, or both.

COMPENSATEDSURFACE may be subscripted either DETECTED or HYPOTHETICAL (also defined in this Glossary).

COORDS $_{\text {ACTUAL }}$ : The coordinates of the point of part surface contact by the tool tip or

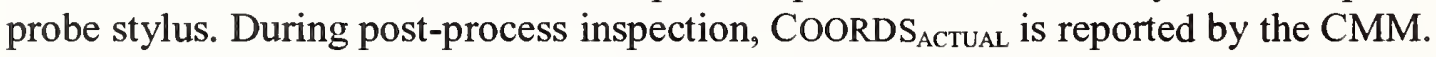

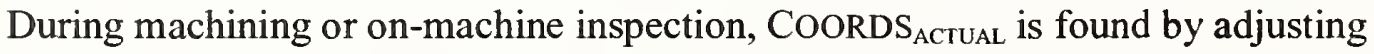
COORDS $_{\text {CONTROLLER }}$ with the GT model to correct machine tool geometric errors. As stated in the preface to this section, all coordinates are expressed with reference to the part coordinate system.

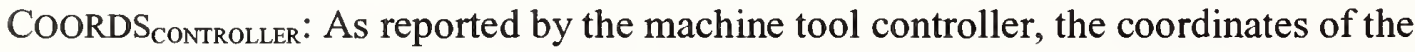
point where the cutting tool contacts the part during machining, or where the probe contacts the part when the probe trips during on-machine inspection. As stated in the preface to this section, all coordinates are expressed with reference to the part coordinate system. Due to geometric-thermal errors in the machine tool, instead of reporting exactly where the machine axes are positioned, the controller may report a slightly different location. Consequently, the point of contact with the part surface is not exactly at COORDS $_{\text {CONTROLLER }}$ 
DETECTED (SURFACE): The actual location of the part surface, as detected by a probe directed either by the machine tool or a CMM. For any specific physical part, this location is known to be unambiguous, however detected. The constant location of the detected surface may be used to compare different locations of the nominal surface as inferred by different inspection procedures. (Such a comparison is based on the assumption that, for any inspection procedure considered, the probe contacts the part so near to the target point that any dimensional difference normal to the part surface at the target point is negligible.)

ERROR $_{\mathrm{MTG}}$ : The machine tool geometric error, at any specified point on the part, is the portion of part error caused by the geometric and thermal characteristics of the machine

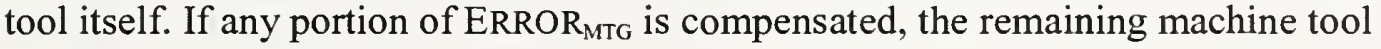
geometric error is ERROR MTG, RESID.

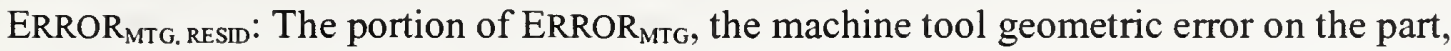
that is not compensated by $\mathrm{COMP}_{\mathrm{MTG}}$, the correction applied using the geometric-thermal model.

ERROR $_{\mathrm{PP}}$ : The total remaining error at any specified point on the finished part, determined by post-process inspection. ERROR $R_{P P}$ is the vector from the nominal location to the corresponding point on the actual surface. The determination of the nominal location and the actual location both result from analysis of CMM inspection data and procedures.

ERROR $_{\mathrm{PROC}}$ : The process error at any specified point on the part, determined by processintermittent inspection-i.e., on-machine inspection of the part in its semi-finished state. At a gauging point, ERROR ${ }_{P R O C}$ is the vector from the nominal location to the corresponding point on the actual (detected) surface. If the part was machined with machine tool geometric error compensation, the coordinates used to calculate ERROR PROC must first be adjusted to discount machine tool geometric errors by adding

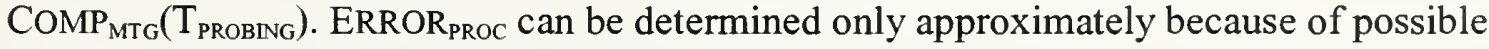
inconsistencies in the GT model. Since the semi-finish cut is similar to the finish cut, the tendency for the process error found on the semi-finished part is expected to also apply to the finished part. The process error is the portion of part error caused by problems with the cutting process, unrelated to machine tool geometry. These errors are attributable to such causes as length, wear, or deflection of the tool; or location, clamping, or deflection of the workpiece.

ERROR $_{\text {PROC, RESID }}$ : The error determined by on-machine inspection of the finished part. If machining was done without process error compensation in effect, ERROR PROC, RESID $=$ ERROR $_{\text {PROC. }}$. If the GT model was used to compensate machine tool errors during

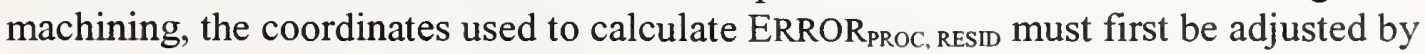
adding $\operatorname{COMP}_{\mathrm{MTG}}\left(\mathrm{T}_{\mathrm{PROBNNG}}\right)$. ERROR $\mathrm{PROC}_{\text {, RESI }}$ can be determined only approximately because of possible inconsistencies in the GT model. 
ERRORCOMPENSATIONVECTOR: A cutting tool position adjustment vector calculated to reduce PARTERROR. An error compensation vector is a SURFACENORMALVECTOR of opposite sign to the error it is intended to reduce. It may be equal to $\mathrm{COMP}_{\mathrm{MTG}}, \mathrm{COMP}_{\mathrm{PROC}}$, or the sum of the two components. The resultant error compensation vector extends from the UNCOMPENSATEDSURFACE HYPOTHETICAL $_{\text {of }}$ a part to the COMPENSATEDSURFACE DETECTED.

ERRORVECTOR: Error vector, in a specific sense, refers to the PARTERROR-a SURFACENORMALVECTOR originating on the nominal surface of a part, and terminating at the detected surface. (More specific information is included in the definition of PARTERROR.) In a general sense, it may refer to any part error component: UNCOMPENSATEDERROR, ERROR $_{\mathrm{MTG}}$, ERROR ${ }_{\mathrm{MTG}}$ RESID, ERROR $_{\mathrm{PP}}$, ERROR EROC , or ERROR ${ }_{\text {PROC, RESID }}$.

GTCOMPENSATEDSURFACE: A part surface produced by machining while compensating machine tool geometric errors, but not compensating process errors. It is located by applying COMP $_{\mathrm{GT}}$ to UNCOMPENSATEDSURFACE $\mathrm{HYPOTHETICAL}_{\text {. }}$.

HYPOTHETICAL (SURFACE): The location where the part surface would be based on a specified set of assumptions that are different from the conditions under which the part was actually fabricated. For example, suppose a part was fabricated with error compensation in effect. Based on the detected location of the actual surface, the calculated location of where it would have been had it been fabricated without error compensation is referred to as UNCOMPENSATEDSURFACE $\mathrm{HYPOTHETICAL}_{\text {. }}$

NOMINALSURFACE ${ }_{\text {Смм}}$ : The theoretically ideal location of the part surface if it were fabricated exactly according to design specifications, based on the part coordinate system determined by CMM setup procedures. The setup procedures attempt to position the part coordinate system as closely as possible to its position when the part was on the machine tool.

NOMINALSURFACE ${ }_{M T}$ : The theoretically ideal location of the part surface if it were fabricated exactly according to design specifications, based on the part coordinate system used by the machine tool during fabrication. The part error is the normal vector from the nominal surface to the detected surface. Therefore, it should be possible to locate the nominal surface from the detected surface using the part error. However, locating

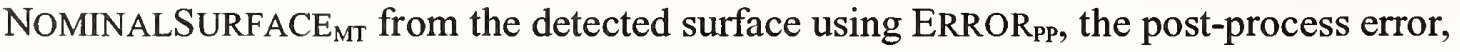
would not be accurate unless the surface were machined without any machine tool geometric errors. This discrepancy is used in this article as a measure of machine tool geometric residual error. This approach to finding NOMINALSURFACE ${ }_{M T}$ results in

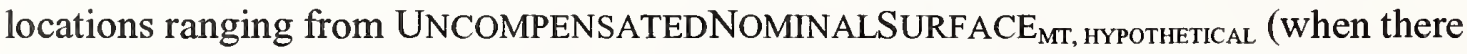
has been no compensation of machine tool geometric errors) to NOMINALSURFACE ${ }_{\text {CMM }}$ (when machine tool geometric errors have been fully compensated). 
PARTERROR: The deviation of a point on a part surface from the nominal location implied for that point in the part design specifications. ${ }^{9}$ As the term is used here, a part error is the surface normal vector originating from a nominal surface location-a point on the theoretical ideal part geometry-and extending to the measured location of the part surface. During dimensional inspection of the part, the probe stylus should approach the gauging point along the surface normal vector. But since a slight probe positioning error is possible, the error vector is calculated as follows. If the vector from the nominal coordinates of the gauging point to the point of probe contact on the part surface is not exactly normal to the nominal surface, then the normal component of that vector is used as the error vector. This convention for calculating the error vector is judged to be a sufficient approximation of the normal error vector at the gauging point, even though the exact error may be slightly different if the tangent of the detected surface is not exactly parallel to the tangent of the nominal surface. When a part surface is machined without applying error compensation, the PARTERROR has the maximum magnitude,

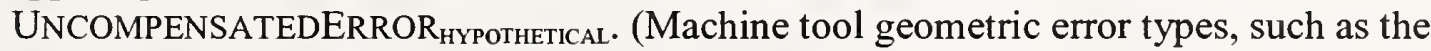
straightness of carriage motion or the squareness between the motions of the carriage and cross-slide, are not addressed.)

POINT $_{\text {ACTUAL }}$ : Any point on the detected part surface. Usually the point of interest is the intersection between the detected surface and the surface normal vector that passes

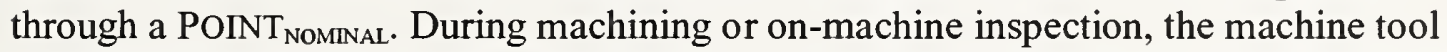
controller reports the coordinates of POINT $_{\text {ACTUAL }}$ to be COORDS CONTROLLER $_{\text {, but the correct }}$ location is COORDS $_{\text {ACTUAL }}$.

POINT $_{\text {NOMINAL }}$ : Any point on a NOMINALSURFACE of a part, especially a gauging point having coordinates specified on the nominal surface.

POINT UNCOMPENSATED $_{\text {: Any point on a detected or hypothetical part surface that was }}$ produced by machining without error compensation. Usually the point of interest is the intersection between the surface and the surface normal vector that passes through a POINT $_{\text {NOMINAL }}$.

SURFACE: The location either where a part surface is detected (subscripted DETECTED) or where it could be if certain assumptions were true (subscripted HYPOTHETICAL). The following types of surfaces and their assumptions are defined in this Glossary: NOMINALSURFACE $_{\mathrm{MT}}$, NOMINALSURFACE $\mathrm{CMM}_{\mathrm{M}}$, COMPENSATEDSURFACE, GTCOMPENSATEDSURFACE, UNCOMPENSATEDSURFACE, and UNCOMPENSATEDNOMINALSURFACE $\mathrm{MT}_{\mathrm{MT}}$.

SURFACENORMALVECTOR: A vector perpendicular to the nominal surface of a part, located at a nominal point of interest.

\footnotetext{
${ }^{9}$ The preferred term for this type of dimensional discrepancy on a part is deviation rather than error, according to the International Vocabulary of Basic and General Terms in Metrology. However, since this article intends to relate the numerous kinds of dimensional discrepancies discussed, instead of using a completely different term for each, they are all called different types of errors.
} 
$\mathrm{T}_{\text {CUTTING: }}$ The set of machine tool temperatures recorded just before the start of a machining session.

$\mathrm{T}_{\mathrm{PROBING}}$ : The set of machine tool temperatures recorded just before the start of an onmachine dimensional inspection session.

UNCOMPENSATEDERROR: A part error defined by a vector originating on a nominal surface and terminating where the surface would result from machining without error compensation.

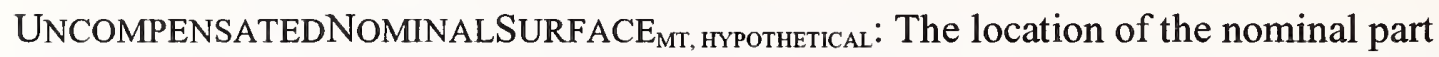
surface with respect to the location where the part surface would result from machining without error compensation, based on the error measured on the machine tool.

UNCOMPENSATEDSURFACE: At any specified point on the part, the location of the part surface if the part was manufactured without any special procedures to compensate process errors or machine tool geometric errors. UNCOMPENSATEDSURFACE may be subscripted either DETECTED or HYPOTHETICAL (also defined in this Glossary). 

